\title{
Effect of A Standardized Extract of Asparagus Officinalis Stem on HSP 70 Induction and Redox Balance in Bovine Cumulus-Granulosa Cells
}

Ho Khoi

Graduate School of Agriculture, Hokkaido University, Sapporo, Hokkaido, 060-8589

Kohei Homma

AMINO UP Co. Itd., Sapporo, Hokkaido

Jun Takanari

AMINO UP Co. Itd., Sapporo, Hokkaido

Hanako Bai

Graduate School of Agriculture, Hokkaido University, Sapporo, Hokkaido, 060-8589

Manabu Kawahara

Graduate School of Agriculture, Hokkaido University, Sapporo, Hokkaido, 060-8589

Khang Nguyen

College of Agriculture, Can Tho University, Can Tho City

Masashi Takahashi ( $\square$ mmasashi@anim.agr.hokudai.ac.jp )

Graduate School of Global Food Resources, Hokkaido University, Sapporo, Hokkaido 060-8589

\section{Research Article}

Keywords: bovine cumulus-granulosa cells, EAS, HSP70, GSH, ROS

Posted Date: June 25th, 2021

DOl: https://doi.org/10.21203/rs.3.rs-640401/v1

License: (a) This work is licensed under a Creative Commons Attribution 4.0 International License. Read Full License 


\section{Abstract}

Heat shock protein 70 (HSP70) is a well-known heat shock (HS)-induced protein that acts as an intracellular chaperone to protect cells against stress conditions. Although HS induces HSP70 expression to acquire stress-resistant ability to cells, HS causes toxicity to cells by increasing reactive oxygen species (ROS). Recently, a standardized extract of Asparagus officinalis stem (EAS), produced from the byproduct of asparagus, was found to induce HSP70 expression without HS and regulate cellular redox balance in the cells. However, the effect of EAS on the function of reproductive cells remains unknown. In the present study, we investigated the effect of EAS on HSP70 induction and oxidative redox balance in cultured bovine cumulus-granulosa(CG) cells. EAS significantly increased HSP70 expression, whereas no effect was observed in HSP27 and - 90 under non-heat stress condition. EAS decreased ROS generation and DNA damage, and increased glutathione (GSH) synthesis both under non-HS and HS conditions. Moreover, EAS synergistically increased $H S P 70$ and HSF1 expression. EAS also increased progesterone (P4) levels in CG cells. HSP70 inhibitor significantly decreased GSH and increased ROS, as well as decreased HSF1, Nrf2, and Keap1 in the presence of EAS. These results suggest that EAS regulates redox balance through HSP70 in bovine CG cells.

\section{Introduction}

Cumulus-granulosa cells surround oocytes and play a vital role in the maturation and acquisition of developmental competence in mammalian oocytes ${ }^{1}$. Cumulus cells and oocytes communicate metabolically via gap junctions, which provide important points of entry for nutrient transfer and signaling between both cell types ${ }^{2}$. The absence of cumulus-granulosa cells has harmful effects on maturation, fertilization, and embryo development in cattle ${ }^{3}$. Cumulus-granulosa cells enhance the nuclear and cytoplasmic maturation of oocytes during maturation ${ }^{4}$ and the fertilization rate during fertilization ${ }^{5}$. In addition to playing an important role in oocyte development, cumulus-granulosa cells protect oocytes against damage caused by oxidative stress during maturation ${ }^{6}$. After ovulation, the remaining cumulus-granulosa cells differentiate into corpus luteal cells to produce progesterone, an important steroid hormone, to maintain pregnancy ${ }^{7}$. In addition, the in vitro environment has a higher concentration of $\mathrm{O}_{2}$, which is a source of ROS, than the in vivo environment ${ }^{8}$. Cumulus cells have been suggested to play a critical role in defending bovine oocytes against cell damage due to ROS production

${ }^{1}$. Moreover, during in vitro maturation, cumulus-oocyte complexes have higher levels of GSH than cumulus-denuded oocytes, and bovine cumulus-granulosa cells contribute to cumulus-oocyte complex GSH synthesis ${ }^{6}$. Therefore, bovine cumulus-granulosa cells play a major role in the generation of GSH, which can reduce ROS production. As a result, the balance between ROS and GSH can prevent cell death by maintaining the balance of the cellular redox status.

The cellular redox status contributes to important cellular functions, such as regulation of proliferation, differentiation, and cell death, and is defined as the balance between oxidants (or pro-oxidants) and antioxidants ${ }^{9}$. ROS are free radicals, such as superoxide anion radicals, hydroxyl radicals, and hydrogen 
peroxide, that cause damage to cells by lipid peroxidation and enzyme inactivation ${ }^{10}$. The upregulation of ROS production can induce cell death signaling through an imbalance in the redox status of the cells 11. In addition, previous studies have evaluated the effect of ROS on DNA damage, which induces toxicity in cells or the death of cells ${ }^{12}$. In contrast, GSH, which is synthesized from the y-glutamyl cycle, is one of the major antioxidants present in mammalian cells and provides a powerful antioxidant defense against oxidative stress ${ }^{13}$. The balance between ROS and GSH can reduce DNA damage by altering the cellular redox status, thus improving cell survival.

HSP70, also called stress protein, is a molecular chaperone that assists in the folding, unfolding, and homeostasis of cellular proteins ${ }^{14}$. Therefore, the main functions of HSP70 allow the cell to survive during several stresses, such as physical, chemical, and environmental stress ${ }^{15}$. Experimental evidence has suggested that HSP70 expression regulates both GSH and ROS generation, indicating that an interrelationship between HSP70 and the redox status exists ${ }^{16}$. Various plant sources have been studied in an attempt to identify HSP70 induction activity. In this context, asparagus (Asparagus officinalis L.) is a potential candidate because of its antioxidant ability ${ }^{17}$. In addition, functional food ingredients are more valuable when they promote the effective use of unused parts. EAS is produced from the unused bottom part of asparagus, and this extract contains active ingredients that enhance HSP70 expression, such as asparagine ${ }^{18}$. In addition, asparagine has been found to increase the HSP70 mRNA levels in a human promyelocytic leukemia cell line ${ }^{18}$. This evidence suggests that EAS is a potential inducer of HSP70, which may regulate the balance between GSH and ROS generation.

Several products, such as paeoniflorin, geranylgeranylacetone, and bimoclomol, have been found to stimulate HSP70 ${ }^{19} 20$. Bimoclomol induced heat shock protein (HSP) under HS conditions, but did not influence HSP activity under non-stress conditions ${ }^{19}$. Paeoniflorin and geranylgeranylacetone increased HSP70 expression under HS conditions in experiments on cells and rats ${ }^{20}$. These data showed that the HSP70 inducer has a synergistic effect with HS on HSP70 expression.

I In the present study, we investigated the effect of EAS on HSP70 induction and oxidative redox balance in cultured bovine cumulus-granulosa(CG) cells.

\section{Results}

\section{Effect of EAS on the induction of HSPs}

To determine the concentration of EAS required to induce HSP genes (HSP27,-70, and - 90) in bovine cumulus-granulosa cells, we examined various concentrations of EAS $(0.5,1$, and $5 \mathrm{mg} / \mathrm{mL})$. A significant increase $(\mathrm{P}<0.05)$ in HSP70 expression was observed after treatment with $5 \mathrm{mg} / \mathrm{mL}$ EAS (Fig. 1a). However, the expression of HSP90 and HSP27 was not influenced by EAS (Fig. 1b and c). Similar to the induction of HSP70, the HSP70 protein levels were significantly increased $(P<0.01)$ by $5 \mathrm{mg} / \mathrm{mL}$ EAS (Fig. 3a, b). Since HSPS are induced by heat shock, we evaluated the effect of EAS on HSP expression 
after $6 \mathrm{~h}$ of $\mathrm{HS}\left(41^{\circ} \mathrm{C}\right)$ treatment by comparing against non-HS conditions in bovine CG cells. Similar to Fig. 1, EAS specifically increased HSP70 expression under non-HS control conditions (Fig. 2a) compared with HSP90 expression (Fig. 2b) and - 27 (Fig. 2c).

HS induced an increase in HSP70 and - 90 expression. However, interestingly, HSP70 was synergistically increased by HS and EAS (Fig. 2a). The immunodetection of HSP70 also showed a similar increase in HSP7O gene expression (Fig. 3c, d).

HSF1 is a transcription factor that induces HSP70 by heat shock ${ }^{24}$. As shown in Fig. 4A, HSF1 expression was significantly increased by HS and EAS, whereas no effect of HS and EAS was observed in HSF2 expression (Fig. 4b).

\section{Effect of EAS on ROS generation}

After HSP70 expression was enhanced by EAS in bovine cumulus-granulosa cells, we investigated the effect of EAS on HSP70 and oxidative and redox balance ${ }^{25}$. As shown in Fig. 5a and c EAS significantly reduced the ROS levels under both non-HS and HS conditions.

\section{Effect of EAS on DNA damage by YH2AX levels}

ROS are known to cause apoptosis associated with mitochondrial dysfunction and single- and doublestrand DNA breaks ${ }^{26}$. Therefore, we hypothesized that EAS could reduce DNA damage by heat shockinduced ROS generation. The levels of $\mathrm{YH} 2 \mathrm{AX}$ were significantly increased $(P<0.05)$ by HS (Fig. $5 b, d)$. The levels of $\mathrm{YH} 2 \mathrm{AX}$ in HS were significantly decreased by EAS.

\section{Effect of EAS on GSH synthesis}

GSH was detected more strongly in the nuclei than in the cytoplasm (Fig. 6a). EAS significantly increased the GSH levels $(P<0.05)$ in non-HS cells $(F i g .6 a, b)$.

Effect of EAS on expression of oxidative stress and redox-regulated genes

To determine whether EAS protects against DNA damage by maintaining the redox status, we focused on genes related to oxidative stress and redox balance. The expression of $G C L$ and $G S$, which are involved in GSH synthesis in mammalian cells ${ }^{27}$, was significantly increased by EAS under non-HS conditions (Fig. $7 a, b)$. Since GSH synthetic pathways, such as GCL and GS activation, are dependent on Nrf2 regulation ${ }^{28}$, we analyzed the expression of Nrf2 and Keap1. As a result, the expression both Nrf2 and Keap1 was found to be significantly increased by HS treatment (Fig. 7c, d). The Nrf2 levels in the HS and HS + EAS (5 $\mathrm{mg} / \mathrm{mL})$ groups were significantly increased compared to the control $(\mathrm{P}<0.01)$. In contrast, the HS + EAS $(5 \mathrm{mg} / \mathrm{mL})$ group had a lower Keap $1 \mathrm{mRNA}$ expression than the control, EAS $(5 \mathrm{mg} / \mathrm{mL})$, and HS groups $(P<0.01)$ (Fig. 7d).

EAS extracted from Asparagus officinalis L., which contains high levels of antioxidants, such as carotenoids, steroidal saponins, and flavonoids ${ }^{29}$. Antioxidant activity has been demonstrated in other 
extracts of this vegetable ${ }^{29}$. Therefore, we analyzed antioxidant enzymes, including SOD1, SOD2, PRDX2, and $P R D X 6$, to evaluate the antioxidant effect of EAS under non-HS conditions. The expression of SOD1 and SOD2 was significantly increased by HS treatment (Fig. 7e, f). Although no effect of EAS was observed on SOD1 and SOD2 expression under non-HS conditions, EAS significantly increased both expression under HS conditions. Similar to the expression patterns of SOD1 and SOD2, EAS significantly increased the expression of PRDX2 and PRDX6 (Fig. 7g, h).

\section{Effect of HSP70 inhibition on redox status of bovine cumulus-granulosa cells treated by EAS}

The high level of HSP70 reduced the levels of ROS and induced GSH levels during EAS treatment, suggesting that HSP70 plays a role in the balance of cellular redox status in bovine cumulus-granulosa cells. We hypothesized that HSP70 induction by EAS triggers the regulation of the balance of ROS and $\mathrm{GSH}$, which is required for maintaining cellular redox status in bovine cumulus-granulosa cells. To test this hypothesis, cells were treated with EAS $(5 \mathrm{mg} / \mathrm{mL})$ and $10 \mu \mathrm{M}$ PES. Cell viability of $10 \mu \mathrm{M}$ PES was 77\% (Supplemental Fig. 1)

Decreased levels of ROS by EAS treatment were significantly increased by PES treatment (Fig. 8a, C). In contrast, the levels of GSH that had been increased by EAS were significantly decreased (Fig. 8b, d). Moreover, the expression of HSF1 and Nrf2 increased by EAS was significantly decreased by the inhibition of HSP70 (Fig. 9a, b). In addition, Keap1 expression was also significantly decreased by the inhibition of HSP70 (Fig. 9c).

\section{EAS increased P4 synthesis}

The role of bovine cumulus-granulosa cells not only supports oocyte development, but also fulfills the endocrine role of steroid hormone secretion ${ }^{30}$. To further investigate the effect of EAS on steroidogenesis, the P4 levels were measured, and were found to be significantly increased by EAS supplementation compared to the control group $(P<0.05)$ (Fig. 10).

\section{Discussion}

EAS has been shown to increase the expression of HSP70 mRNA and protein in HeLa cells, neuronal cell NG108-15, and hepatocyte cells ${ }^{31}, 32,33$. Moreover, HSP70 overexpression increased the GSH/GSH disulfide ratio while reducing the ROS levels under hypoxia and glucose deprivation conditions ${ }^{16}$. Therefore, the current study investigated whether EAS increases HSP70 expression. GSH is an antioxidant enzyme whose synthesis reduces heat shock-induced ROS generation with DNA damage to maintain the redox status in bovine cumulus-granulosa cells.

In the present study, EAS significantly increased the HSP70 mRNA and protein levels in bovine cumulusgranulosa cells at $5 \mathrm{mg} / \mathrm{mL}$ during $6 \mathrm{~h}$ of incubation. This result is consistent with a previous study by ${ }^{33}$, who studied the dose and incubation time of EAS treatment in cultured hepatocyte cells. In addition, HeLa 
cells also increased HSP70 mRNA and protein expression when treated with a lower dose of EAS (4 $\mathrm{mg} / \mathrm{mL})$, but had a longer incubation time $(24 \mathrm{~h})$ than in the current study $(6 \mathrm{~h})^{31}$. The variation in the dose of EAS in cells may be due to differences in cell type and culture conditions. HSP70 expressionenhancing activity by EAS may arise from asparagine, which has been found to elevate HSP70 in human monocyte HL-60 cells ${ }^{18}$. On the other hand, resistance to anti-cancer drugs due to overexpression of HSP27 and HSP90 has been reported in several studies, but the expression of HSP27 and HSP90 in bovine cumulus-granulosa cells was not affected by EAS ${ }^{34}$. Therefore, our results confirm the unique effect of EAS on HSP70 induction in bovine cumulus-granulosa cells under non-HS conditions.

In vivo and in vitro studies have shown a synergistic effect between HS and heat shock protein-inducing compounds on HSP70 expression ${ }^{20}, 35$. In this study, HSP70 induction by EAS occurred in both non-HS and HS conditions, and it was highest under HS conditions. Paeoniflorin, an HSP70-inducing compound derived from peony (Paeonia lactiflora), increased HSP70 expression under HS conditions in HeLa cells 20. In addition, geranylgeranylacetone, a non-toxic HSP70 inducer, induced HSP70 levels in the brains of heatstroke rats ${ }^{35}$. These data support that the combination of EAS with HS synergistically affects HSP70 induction in bovine cumulus-granulosa cells. The induction of HSF1, which is one of the main transcription factors of HSP70, by EAS has been reported in neuronal cells NG108-15 ${ }^{33}$. The significant increase in HSF1 gene expression by EAS in the present study supports the involvement of EAS in the HSP70 inducing pathway in bovine cumulus-granulosa cells. It is known that HSF1 is also available in non-stressed cells and binds to HSP70 as an inert monomer ${ }^{36}$. Under cellular stress, HSF1 is activated and releases HSP70 to prevent the formation of misfolded polypeptides ${ }^{36}$. In the present study, HSF1 gene expression was induced by EAS supplementation in both non-HS and HS conditions, and it was highest with EAS supplementation under HS conditions. In addition, the activator of HSF1 can also be stimulated by endogenous metabolites, synthetic compounds, and phytochemicals ${ }^{37}$. Therefore, HSF1 enhancement by EAS was induced by the phytochemical compounds of asparagus, such as carotenoids, steroidal saponins, and flavonoids ${ }^{29}$. These data suggest that EAS and HS have synergistic effects on the induction of HSF1 in bovine cumulus-granulosa cells. HSF2 is a heat shock transcription factor coexpressed with HSF1 that is activated in response to distinct developmental cues or differentiation stimuli ${ }^{36}$. The interaction between HSF1 and HSF2 was discovered through their coiled-coil domains adjacent to their DNA-binding domains ${ }^{37}$, however, HSF2 was not affected by EAS in the current study. In the present study, supplementation with EAS led to increased HSP70 expression under non-HS conditions. However, HSF1 expression was only induced under HS conditions with a synergistic effect by EAS. In addition, treatment with an HSP70 inhibitor reduced HSF1 gene expression. The inconsistency with results from previous studies may be due to the involvement of several factors. EAS may regulate the expression of HSP70 not only through HSF1 gene expression but also through other regulatory mechanisms. Additionally, research on different species and cell types has led to reports of different regulatory effects of EAS on HSF1 gene expression ${ }^{33}$. Hence, it is conceivable that an increase in HSP70 expression by EAS is induced as a result of the asparagine content and enhancement of HSF1, with EAS exerting synergistic effects with HS on HSP70 induction. 
Several studies have indicated that HSP70 has apoptosis-suppressive effects and anti-inflammatory activity, indicating that HSP70 exerts a cytoprotective function against various stresses ${ }^{38}$. In addition, the overexpression of HSP70 reduces ROS induced by hypoxia and glucose deprivation ${ }^{16}$. These results indicate that EAS with unique inducible HSP70 could protect cells against ROS under various stress conditions. Moreover, EAS was found to significantly reduce the amyloid beta peptide-induced production of ROS in differentiated PC12 cells ${ }^{39}$. In the present study, EAS treatment significantly inhibited ROS expression in both normal and HS conditions in bovine cumulus-granulosa cells by activating GSH generation and antioxidant enzymes, such as SOD and PRDX. SOD is the first line of defense against ROS, and is comprised of three classes: Cu/Zn SOD (SOD1), Mn SOD/Fe SOD (SOD2), and Ni SOD 40 . The reaction of the superoxide anion $\left(\mathrm{O}_{2}{ }^{--}\right)$to form hydrogen peroxide $\left(\mathrm{H}_{2} \mathrm{O}_{2}\right)$ is catalyzed by SOD ${ }^{40}$. PRDX has six isoforms, PRDX1, 2, and 6 in the cytosol, PRDX3 in mitochondria, PRDX4 in the endoplasmic reticulum, and PRDX5 in both mitochondria and peroxisomes ${ }^{41}$. PRDX contributes to the reduction of $\mathrm{H}_{2} \mathrm{O}_{2}$ to $\mathrm{H}_{2} \mathrm{O}^{41}$. In addition, $\mathrm{GSH}$ concentration is used by PRDX6, which contributes to the elimination of $\mathrm{H}_{2} \mathrm{O}_{2}$ production ${ }^{42}$. $\mathrm{GSH}$ has been shown to play an important role in antioxidant defense by interacting with ROS ${ }^{43}$. Moreover, it is known that ROS activate c-Jun N-terminal kinase protein, which also increases under HS conditions ${ }^{44}$. EAS clearly reduced the c-Jun $\mathrm{N}$-terminal kinase protein induced by hydrogen peroxide in fibroblast cells ${ }^{45}$. Quercetin, a flavonoid in asparagus, reduced the ROS levels while enhancing the antioxidant activity of bovine embryos under hyperoxic conditions ${ }^{46}$. In conclusion, EAS reduced heat shock-related ROS generation in bovine cumulus-granulosa cells, which can be explained by the upregulation of GSH generation together with antioxidant enzymes and the downregulation of c-Jun $\mathrm{N}$-terminal kinase protein.

ROS-induced damage can cause both single- and double-stranded DNA breaks ${ }^{26}$. In the present study, EAS reduced $\gamma H 2 A X$ expression under non-HS conditions, however, the difference was not significant. Moreover, EAS significantly reduced the $\mathrm{YH} 2 \mathrm{AX}$ levels under $\mathrm{HS}$ conditions. ROS generation from normal cellular metabolism and HS induces DNA damage in cells ${ }^{47}$. In a previous study, EAS was shown to reduce cell damage induced by nitric oxide donor sodium nitroprusside or the hypoxia mimic reagent cobalt chloride of NG108-15 cells ${ }^{32}$. HSP70 has the ability to repair DNA damage caused by HS ${ }^{26}$. In the present study, HSP70 induction by the synergistic effect of EAS and HS contributed to reducing DNA damage in bovine cumulus-granulosa cells supplemented with EAS under HS conditions. Moreover, GSH also contributes to DNA repair activity, and the expression of GSH in the nucleus enhances protection against DNA damage ${ }^{48}$. In the present study, GSH generation was increased by EAS in bovine cumulusgranulosa cells under non-stress and HS conditions; however, it was only significantly higher under nonstress conditions. These results indicate that EAS reduced DNA damage under non-HS conditions and was within the acceptable range of non-toxic levels of ROS production due to the enhancement of HSP70 and GSH levels.

GSH is a pivotal intracellular antioxidant that exerts potential cytoprotective ability by protecting cells against oxidants and electrophiles ${ }^{49}$. In our study, EAS increased GSH in both non-HS and HS conditions, 
but only cells supplemented with EAS under non-HS conditions were statistically significantly different when compared with the control group. In agreement with this observation, previous reports have suggested that the overexpression of HSP70 enhances GSH expression ${ }^{16}$. However, the GSH levels in the control group were similar to those in the HS group, which were exposed for $6 \mathrm{~h}$ at $41^{\circ} \mathrm{C}$. In HeLa cells, HS treatment for 1,2 , or $3 \mathrm{~h}$ at $42^{\circ} \mathrm{C}$ resulted in the highest increase in $\mathrm{GSH}$ at $1 \mathrm{~h}$ and the lowest at $3 \mathrm{~h} 28$. GSH biosynthesis is required by the action of two ATP-dependent enzymes: GCL, which assembles the formation of c-glutamyl-cysteine from glutamate-cysteine, and GS, which is involved in the ligation of cglutamyl-cysteine to glycine in another ATP-dependent reaction to yield $\mathrm{GSH}^{27}$. Our results showed that EAS increased the expression of GCL and GS under non-HS conditions. The transcription factor Nrf2, which has the potential to induce GCL and GS, is activated by ROS production ${ }^{50}$. The transcription factor Nrf2 binds to Keap1 under normal conditions, known as the Nrf2/Keap1 signaling pathway, and is translocated to the nucleus in the presence of $\mathrm{HS}^{51}$. In the nucleus, Nrf2 binds to antioxidant response elements (ARE) via the DNA-binding domain of small Mafs, thereby activating the transcription and translation of GCL and GS ${ }^{51}$. Moreover, HSF1 may induce Nrf2 by activating p62, which can separate Nrf2 from Keap $1{ }^{52}$. In this study, the GSH levels were not decreased by HS because of the compensatory effect of HSF1 with Nrf2, which can influence the GSH levels after $6 \mathrm{~h}$ of HS treatment. Therefore, there is a need to study the effect of HS treatment on GSH synthesis and the induction of genes. A previous study showed that reduced Keap1 expression is logically related to the induction of Nrf2 ${ }^{53}$. Together with the induction of Nrf2, EAS supplementation reduced Keap1 and induced HSF1 expression in the present study. In addition, supplementation of quercetin, a plant-derived flavonoid, comprised mainly of polyphenolic compounds from fruits and vegetables, induced Nrf2 expression in bovine embryos ${ }^{46}$. EAS treatment increased the Nrf2 protein levels in NG108-15 neuronal cells ${ }^{32}$. In conclusion, EAS increased GSH expression and y-glutamyl cycle mRNA expression due to Nrf2, which was induced by the compensation effect of HSF1 with Nrf2 and the antioxidant content of EAS.

The higher expression of antioxidant enzyme genes in the HS group in the present study was similar to that reported in a previous study, in which HS induced SOD and PRDX expression in pig skeletal muscle 54 and HeLa cells ${ }^{28}$, respectively. In another study, HS was reported to upregulate HSP70 and SOD2 in Chinese hamster lung fibroblast V79 cells ${ }^{44}$. Interestingly, the heat shock protein family and antioxidant system reduce the harmful effects of ROS ${ }^{55}$. In the present study, EAS increased HSP70 expression, antioxidant enzymes, and reduced ROS levels. Nrf2 expression has been shown to induce PRDX activity in HeLa cells ${ }^{27}$ and SOD activity in mesenchymal stem cells ${ }^{56}$. The binding of Nrf2 to ARE activates PRDX and SOD activity ${ }^{27} 56$. In this study, Nrf2 expression was highest in bovine cumulus-granulosa cells treated with EAS under HS conditions, indicating that the induction of PRDX and SOD was due to Nrf2 expression. EAS extracted from asparagus (Asparagus officinalis L.) contains high levels of antioxidant, including carotenoids, steroidal saponins, and flavonoids ${ }^{29}$. In addition, quercetin, which is one of the six subclasses of flavonoid compounds, increased the expression of Nrf2 and antioxidant genes, such as PRDX1 and SOD1 ${ }^{46}$. Therefore, the enhanced antioxidant activity of EAS treatment results from the induction of Nrf2 expression and the antioxidant content of asparagus (Asparagus officinalis L.). 
PES has been shown to inhibit the function of HSP70 ${ }^{57}$. In the present study, PES reversed the effect of EAS on the GSH and ROS levels, indicating that HSP70 induction by EAS regulated the levels of GSH and ROS in bovine cumulus-granulosa cells. A previous study reported a correlation between the transcription factors Nrf2 and HSF1 for the protection of cells ${ }^{58}$. There is evidence that Nrf2 and HSF1 compensate each other; the induction of HSP70 by methionine deprivation is dependent on Nrf2 but independent of HSF1 ${ }^{59}$. Both Nrf2 and HSF1 play important roles in cellular redox processes due to their ability to influence the levels of HSP70 and GSH. Therefore, distinct cell survival pathways, such as the HS response and Keap1/Nrf2/ARE pathway, are regulated by Nrf2 and HSF1 ${ }^{51}$. In the present study, PES also reversed the induction effect of both Nrf2 and HSF1. PES reduced the nuclear translocation of the nuclear factor-KB (NF-KB) pathway, which regulates the transcription of various gene families, including stress response, apoptosis, and receptor genes, and influences cell survival, differentiation, and proliferation ${ }^{60}$. The nuclear translocation of NF-KB p65 enhances the ability of Nrf2 and plays a role in the antioxidant response in human kidney-2 cells ${ }^{61}$. In addition, HSF1 activation in intestinal epithelial cells during HS is regulated by the NF-KB pathway ${ }^{62}$. Moreover, PES reduced the levels of Keap1, which combined with Nrf2 to regulate the antioxidative protection system ${ }^{51}$. These results indicate that HSP70 induction by EAS improved the redox balance by regulating the ROS and GSH levels via regulating the heat shock response through HSF1 and the antioxidant response through the Nrf2/Keap1 pathway in bovine cumulus-granulosa cells.

The beneficial effect of EAS on P4 synthesis demonstrated in the present study was similar to that reported in a previous study, in which the oral administration of asparagus root extract enhanced P4 levels in rats ${ }^{63}$. P4 levels were enhanced by EAS was due to the presence of steroid saponins, such as sarsaponin, protodioscin, and diosgenin, in asparagus extract, which act as precursors of progesterone 63 . This indicated that bovine cumulus-granulosa cells were important for reproductive function, especially steroidogenesis. As such, these findings indicate that EAS contributed to the improvement of P4 synthesis in bovine cumulus-granulosa cells.

In conclusion, EAS was shown to induce HSP70 under non-HS conditions, exerting a synergistic effect with HS on HSP70 induction in bovine cumulus-granulosa cells. Furthermore, EAS had beneficial effects, reducing the DNA damage induced by ROS, as well as increasing GSH synthesis and antioxidant enzyme levels to maintain the redox status, in addition to the P4 levels, in bovine cumulus-granulosa cells. HSP70 induced by EAS regulated the Nrf2/Keap1 pathway and HSF1 transcription factor levels, which contributed to the ROS and GSH levels in bovine cumulus-granulosa cells.

Taken together, the findings presented in this study demonstrate that EAS has potential uses in the regulation of reproductive functions by reducing physical stress and improving the properties of reproductive cells.

\section{Methods}


EAS was provided by Amino Up Co., Ltd. (Sapporo, Japan), produced from asparagus (A. officinalis L.) grown in Hokkaido. EAS was manufactured according to a previously described method ${ }^{21}$.

\section{Culture of bovine cumulus-granulosa cells}

Bovine ovaries were collected from a local abattoir and transported to the laboratory at $20^{\circ} \mathrm{C}$. The ovaries were washed several times with sterile saline solution. Cumulus-oocyte complexes were aspirated from follicles (2-8 $\mathrm{mm}$ in diameter) using a disposable 18-gauge needle attached to a 10-ml syringe. After picking up the $\mathrm{COCs}$, the bovine cumulus-granulosa cells remaining in the follicular fluid were used for the experiment. These cells were cultured in $5 \%$ fetal bovine serum (FBS) in Dulbecco's modified Eagle's medium (high glucose) (DMEM) (Wako, Osaka, Japan) supplemented with $0.06 \mathrm{~g} / \mathrm{l}$ penicillin $\mathrm{G}$ potassium (Nacalai Tesque, Kyoto, Japan) and $0.1 \mathrm{~g} / \mathrm{L}$ streptomycin sulfate (Nacalai Tesque) at $38.5^{\circ} \mathrm{C}$ under $5 \% \mathrm{CO}_{2}$ in air. After reaching confluency, bovine cumulus-granulosa cells were washed with calcium- and magnesium-free phosphate-buffered saline (PBS) (-) and separated with PBS (-) containing $0.05 \%$ trypsin and $0.53 \mathrm{mM}$ EDTA for $2 \mathrm{~min}$ at $38.5^{\circ} \mathrm{C}$ in a $\mathrm{CO}_{2}$ incubator. After supplementation with 5\% FBS in DMEM to inhibit trypsin activity, the cell suspension was centrifuged at $1,200 \times g$ for $3 \mathrm{~min}$.

Viable cells were plated at a density of $1.0 \times 10^{5}$ cells $/ \mathrm{mL}$ onto 4-well culture plates (Thermo Fisher Scientific) for analysis of gene expression and western blot or 8-well slides and chambers (SPL Life Sciences Co., Ltd, Pocheon, Korea) for ROS, GSH, HSP70, and YH2AX. The cells were then cultured at $38.5^{\circ} \mathrm{C}$ under $5 \% \mathrm{CO}_{2}$ in air. After cells became $70 \%$ confluent, the medium was replaced with $0.9 \mathrm{ml}$ of $5 \%$ FBS in DMEM together with $0.1 \mathrm{ml}$ of EAS stock solution in PBS (-), and $0.1 \mathrm{ml}$ of PBS (-) was added in control group. After that, the cells were cultured at $38.5^{\circ} \mathrm{C}$ under $5 \% \mathrm{CO}_{2}$ in air for non-HS conditions or $41^{\circ} \mathrm{C}$ under $5 \% \mathrm{CO}_{2}$ in air under $\mathrm{HS}$ conditions. A previous study showed that the maximum rectal temperature in cows was $41.1^{\circ} \mathrm{C}$ during summer (heat load index $>86$ ) ${ }^{22}$

\section{Experiment design}

Cells were cultured at $38.5^{\circ} \mathrm{C}$ for $6 \mathrm{~h}$ with $0.5,1$, and $5 \mathrm{mg} / \mathrm{mL}$ of EAS for mRNA expression of $H S P 27$, $H S P 90, H S P 70$, and $5 \mathrm{mg} / \mathrm{mL}$ of EAS for western blot analysis of $\mathrm{HSP} 70$ at $38.5^{\circ} \mathrm{C}$ for $6 \mathrm{~h}$. To compare the effect of EAS under non-HS and HS conditions, cells were cultured at $38.5^{\circ} \mathrm{C}$ and $41^{\circ} \mathrm{C}$ for $6 \mathrm{~h}$ with 5 $\mathrm{mg} / \mathrm{mL}$ of EAS for immunostaining, fluorescent staining, mRNA expression of HSP27, HSP90, HSP70, heat shock factor (HSF) 1, HSF2, glutathione synthetase(GS), glutamate cysteine ligase (GCL), nuclear factor erythroid 2-related factor2 (Nrf2), Kelch-like ECH-associated protein 1 (Keap1) Keap1, Superoxide dismutase (SOD) 1, SOD2, peroxiredoxin (PRDX)-2, and PRDX-6.

To inhibit HSP70 activity, cells with $5 \mathrm{mg} / \mathrm{mL}$ of EAS supplementation were treated with $10 \mu \mathrm{M}$ pifithrin- $\mu$ (PES) or without PES under non-HS conditions for $12 \mathrm{~h}$.

To determined suitable concentration of PES, cells were treated with $5 \mu \mathrm{M}, 10 \mu \mathrm{M}, 20 \mu \mathrm{M}$ PES at non HS condition for $12 \mathrm{~h}$ and cell viability was analysed by Live-Dead Cell Staining Kit (ALX-850-249, Enzo Life 
Sciences AG, Lausen, TX, USA) according to the instructions by the manufacturer.

To determine the influence of EAS on progesterone synthesis, CG cells were cultured at $38.5^{\circ} \mathrm{C}$ for $12 \mathrm{~h}$ with $5 \mathrm{mg} / \mathrm{mL}$ of EAS.

\section{RNA extraction and quantitative reverse-transcription polymerase chain reaction (RT-qPCR)}

The cells were collected with a cell scraper and subjected to RNA extraction using ISOGEN II. All RNA samples were stored in a freezer at $-80^{\circ} \mathrm{C}$ until use. RNA concentration was measured by spectrophotometry (NanoDrop ND-2000; Thermo Fisher Scientific). Complementary DNA was synthesized by reverse transcription using the ReverTra Ace ${ }^{\circledR}$ qPCR RT Master Mix with gDNA remover (Toyobo Life Science, Osaka, Japan) according to the manufacturer's instructions using a thermal cycler (Astec GeneAtlas Type G Thermal Cycler; ASTEC, Fukuoka, Japan). All cDNA samples were stored in a freezer at $-30^{\circ} \mathrm{C}$ until further use. Specific primers (Supplementary Table 1) were designed using Primer-BLAST (http://www.ncbi.nlm.nih.gov/tools/primer-blast/). The relative expression levels were assessed via qRTPCR using a LightCycler® Nano (Roche Diagnostics, Basel, Switzerland) and THUNDERBIRDTM SYBR ${ }^{\circledR}$ qPCR Mix (Toyobo Life Science) at a final primer concentration of $0.5 \mu \mathrm{M}$ for each primer. The thermal cycling conditions were as follows: 1 cycle at $95^{\circ} \mathrm{C}$ for $30 \mathrm{~s}$ (denaturation), followed by 45 cycles at $95^{\circ} \mathrm{C}$ for $10 \mathrm{~s}$ (denaturation), $55^{\circ} \mathrm{C}$ for $15 \mathrm{~s}$ (primer annealing), and $72^{\circ} \mathrm{C}$ for $30 \mathrm{~s}$ (extension). Relative mRNA abundance was calculated via the $\Delta \Delta \mathrm{Ct}$ method using $\mathrm{H} 2 \mathrm{AFZ}$ as a reference gene.

\section{Western blot analysis}

Bovine cumulus-granulosa cells were lysed in 1\% SDS (Nacalai Tesque), 1\% 2-mercaptoethanol (Nacalai Tesque), $20 \%$ glycerol (Nacalai Tesque), and $50 \mathrm{mM}$ Tris- $\mathrm{HCl}\left(\mathrm{pH} \mathrm{6.8)}\right.$ and denatured at $95^{\circ} \mathrm{C}$ for 5 min. Sample solutions were separated by electrophoresis on 10-20\% gradient SDS-polyacrylamide precast gels (Atto Corporation, Tokyo, Japan). Pre-stained marker proteins with known BlueStar (range, 10-180 kDa) (cat. no. MWP03; Nippon Genetics Co., Ltd., Tokyo, Japan) were run simultaneously as standards. The electrophoretically separated proteins were transferred onto PVDF membranes using an iBlot Gel Transfer System (Invitrogen, Thermo Fisher Scientific Inc., Massachusetts, USA). The membranes were incubated in 4\% skim milk (FUJIFILM Wako Pure Chemical Corporation, Osaka, Japan) for 10 min and then washed three times with Tris-buffered saline and Tween-20 (TBS-T) at room temperature. Membranes were incubated with rabbit anti-human HSP70 polyclonal (1:1,000 dilution) (SPC-103; StressMarq Biosciences Inc.) and $\beta$-Actin monoclonal (1:1,000 dilution) (cat. no. 66009-1-lg; Proteintech Group, Rosemont, USA) at $4^{\circ} \mathrm{C}$ overnight. After three washes with TBS-T, the membranes were incubated with HRP-labeled anti-rabbit IgG for HSP70 (1:25,000 dilution) (cat. no. NA934; GE Healthcare, Buckinghamshire, UK) or anti-mouse IgG secondary antibody for $\beta$-actin (1:25,000 dilution) (cat. no. NA931; GE Healthcare, Buckinghamshire, UK) or at room temperature for $1 \mathrm{~h}$. Primary and secondary antibodies were diluted with an immunoreaction enhancer, Can Get Signal (Toyobo). Membranes were washed extensively with TBS-T before detection of bound antibodies using the WSE-7120EzWestLumi 
plus (Atto Corporation, Tokyo, Japan) according to the manufacturer's instructions. Chemiluminescent signals were captured using the ChemiDoc System (Bio-Rad) and analyzed using ImageJ software.

\section{Immunostaining for HSP70 and YH2AX}

Bovine cumulus-granulosa cells were washed with PBS (-) and fixed in 4\% paraformaldehyde diluted with PBS (-) for $15 \mathrm{~min}$. After washing three times with PBS (-) for $5 \mathrm{~min}$, the samples were permeabilized with PBS (-) containing $0.2 \%(\mathrm{v} / \mathrm{v})$ Triton X-100 for 10 min. After washing with PBS (-), the cells were blocked with $2 \%(\mathrm{w} / \mathrm{v})$ BSA (Sigma-Aldrich) in PBS (-) for $1 \mathrm{~h}$ at room temperature. The samples were washed with PBS (-), incubation with a Rabbit Anti-Human HSP70 Polyclonal (SPC-103; Stress Marq Biosciences Inc.) diluted 1:500 with 0.1\% (w/v) BSA (Sigma-Andrich) or primary rabbit polyclonal antibody for YH2AX (ab11174; Abcam, Cambridge, MA, USA) diluted 1:1,000 in PBS (-) at $4^{\circ} \mathrm{C}$ overnight, was performed for immunoreaction. The samples were washed three times with PBS $(-)$ for 5 min each and incubated for $1 \mathrm{~h}$ with a fluorescein-conjugated secondary antibody (Alexa Fluor ${ }^{\circledR} 488$ donkey anti-rabbit IgG) (A21206; Thermo Fisher Scientific) diluted 1:500 for HSP70 or 1:1,000 for $\mathrm{YH} 2 \mathrm{AX}$ with $0.1 \%(\mathrm{w} / \mathrm{v}) \mathrm{BSA}$ (Sigma-Aldrich) in PBS (-) at room temperature. Cells were then washed with PBS $(-)$ for $5 \mathrm{~min}$, and $10 \mu \mathrm{L}$ of the mounting solution (Fluoro-KEEPER Anti fade Reagent) (Non-Hardening Type with DAPI; Nacalai Tesque) was added to the samples, which were then covered with a cover glass. Then, $\mathrm{YH} 2 \mathrm{AX}$ and HSP70 staining was examined under a fluorescent microscope with an EVOS ${ }^{\mathrm{TM}}$ M5000 Imaging System (Invitrogen, Thermo Fisher Scientific Inc., Massachusetts, USA). Fluorescence intensity was quantitated using ImageJ software.

\section{ROS and GSH staining and detection}

Cells were washed with PBS $(-)$ and treated with $5 \mu \mathrm{M}$ CellROX® Oxidative Stress Reagents (cat. no. C10444; Life Technologies, Carlsbad, CA, USA) for ROS staining, or $20 \mu \mathrm{M}$ ThiolTracker ${ }^{\mathrm{TM}}$ Violet (cat. no. T10095, Molecular Probes, Eugene, OR, USA) for staining the reduced form of GSH. After each staining, the cells were incubated for $30 \mathrm{~min}$ at $37^{\circ} \mathrm{C}$.

Fluorescence images were acquired using an EVOS $^{\text {TM }}$ M5000 imaging system (Thermo Fisher Scientific Inc.). Fluorescence intensity was quantitated using ImageJ software. For corrected total cell fluorescence (CTCF), we used the following formulas ${ }^{23}$.

CTCF $=$ integrated density - (total area of selected cell $\times$ mean fluorescence of background readings)

CTCF per cell $=$ CTCF $/$ Ncells

where "Integrated Density" is the total cell area is the integrated intensity of the pixels for all cells in the image, total cell area is the number of pixels of all of the cells, background fluorescence is the average mean gray value of nearby regions containing no cells, and Ncells is the number of cells in the image.

\section{P4 measurement}


After $12 \mathrm{~h}$ of incubation, the culture medium was collected and spun down. The supernatant of the culture medium was used for P4 measurement by ELISA.

\section{Statistical analysis}

All data are shown as the mean \pm standard error of the mean (SEM). Analysis of variance (ANOVA), Tukey's test, and Student's t-test were performed using R (version 3.5.3; https://www.r-project.org/). Statistical significance was set at $\mathrm{P}<0.05$.

\section{Declarations}

\section{Acknowledgements}

This study was supported by a Grant-in-Aid for Scientific Research from the Tojuro lijima Foundation for Food Science and Technology.

We would like to thank Editage (www.editage.com) for English language editing.

\section{Author contributions statement}

M.T. conceived the experiments, H.T.K mainly conducted the experiments, H.B. and M.K. supported bovine ovarian cell collection, K.H and J. T. conducted the EAS purification, providing and data analysis, H.T.K, T.K.K. and M.T. analysed the results. All authors reviewed the manuscript.

\section{Additional information}

There are no conflicts of interest to declare.

\section{References}

1. Fatehi, A., Roelen, B., Colenbrander, B., Schoevers, E., Gadella, B., Bevers, M., \& Van den Hurk, R. Presence of cumulus cells during in vitro fertilization protects the bovine oocyte against oxidative stress and improves first cleavage but does not affect further development. Zygote 13, 177-185, doi:doi:10.1017/S0967199405003126 (2005).

2. Russell, D. L., Gilchrist, R. B., Brown, H. M. \& Thompson, J. G. Bidirectional communication between cumulus cells and the oocyte: Old hands and new players? Theriogenology 86, 62-68, doi:10.1016/j.theriogenology.2016.04.019 (2016).

3. Leibfriedrutledge, M. L., Critser, E. S., Parrish, J. J. \& First, N. L. INVITRO MATURATION AND FERTILIZATION OF BOVINE OOCYTES. Theriogenology 31, 61-74, doi:10.1016/0093-691x(89)905645 (1989).

4. Suzuki, H., Jeong, B. S. \& Yang, X. Z. Dynamic changes of cumulus-oocyte cell communication during in vitro maturation of porcine oocytes. Biology of Reproduction 63, 723-729, doi:10.1095/biolreprod63.3.723 (2000). 
5. Nandi, S., Chauhan, M. S. \& Palta, P. Influence of cumulus cells and sperm concentration on cleavage rate and subsequent embryonic development of buffalo (Bubalus bubalis) oocytes matured and fertilized in vitro. Theriogenology 50, 1251-1262, doi:10.1016/s0093-691x(98)00224-6 (1998).

6. Tatemoto, H., Sakurai, N. \& Muto, N. Protection of porcine oocytes against apoptotic cell death caused by oxidative stress during in vitro maturation: Role of cumulus cells. Biology of Reproduction 63, 805-810, doi:10.1095/biolreprod63.3.805 (2000).

7. Abedel-Majed, M. A., Romereim, S. M., Davis, J. S. \& Cupp, A. S. Perturbations in Lineage Specification of Granulosa and Theca Cells May Alter Corpus Luteum Formation and Function. Frontiers in Endocrinology 10, doi:10.3389/fendo.2019.00832 (2019).

8. Luvoni, G. C., Keskintepe, L. \& Brackett, B. G. Improvement in bovine embryo production in vitro by glutathione-containing culture media. Molecular Reproduction and Development 43, 437-443, doi:10.1002/(sici)1098-2795(199604)43:4<437::aid-mrd5>3.0.co;2-q (1996).

9. Hiroi, M. et al. Regulation of apoptosis by glutathione redox state in PC12 cells exposed simultaneously to iron and ascorbic acid. Free Radical Biology and Medicine 38, 1057-1072, doi:10.1016/j.freeradbiomed.2005.01.001 (2005).

10. Guerin, P., El Mouatassim, S. \& Menezo, Y. Oxidative stress and protection against reactive oxygen species in the pre-implantation embryo and its surroundings. Human Reproduction Update 7, 175189, doi:10.1093/humupd/7.2.175 (2001).

11. Murdoch, W. J. Inhibition by oestradiol of oxidative stress-induced apoptosis in pig ovarian tissues. Journal of Reproduction and Fertility 114, 127-130 (1998).

12. Kuo, L. J. \& Yang, L. X. gamma-H2AX - A novel biomarker for DNA double-strand breaks. In Vivo 22, 305-309 (2008).

13. Meister, A. METABOLISM AND FUNCTION OF GLUTATHIONE - AN OVERVIEW. Biochemical Society Transactions 10, 78-79, doi:10.1042/bst0100078 (1982).

14. Saibil, H. Chaperone machines for protein folding, unfolding and disaggregation. Nature Reviews Molecular Cell Biology 14, 630-642, doi:10.1038/nrm3658 (2013).

15. Kregel, K. C. Heat shock proteins: modifying factors in physiological stress responses and acquired thermotolerance. Journal of Applied Physiology 92, 2177-2186, doi:10.1152/japplphysiol.01267.2001 (2002).

16. Guo, S. H., Wharton, W., Moseley, P. \& Shi, H. L. Heat shock protein 70 regulates cellular redox status by modulating glutathione-related enzyme activities. Cell Stress \& Chaperones 12, 245-254, doi:10.1379/csc-265.1 (2007).

17. Kim, B. Y. et al. Effects of Asparagus officinalis Extracts on Liver Cell Toxicity and Ethanol Metabolism. Journal of Food Science 74, H204-H208, doi:10.1111/j.1750-3841.2009.01263.x (2009).

18. Inoue, S. et al. Isolation and Structure Determination of a Heat Shock Protein Inducer, AsparagusDerived Proline-Containing 3-Alkyldiketopiperazines (Asparaprolines), From a Standardized Extract of Asparagus officinalis Stem. Natural Product Communications 15, doi:10.1177/1934578x20914681 (2020). 
19. Vigh, L. et al. Bimoclomol: A nontoxic, hydroxylamine derivative with stress protein-inducing activity and cytoprotective effects. Nature Medicine 3, 1150-1154, doi:10.1038/nm1097-1150 (1997).

20. Yan, D., Saito, K., Ohmi, Y., Fujie, N. \& Ohtsuka, K. Paeoniflorin, a novel heat shock protein-inducing compound. Cell Stress \& Chaperones 9, 378-389, doi:10.1379/csc-51r.1 (2004).

21. Ito, T. et al. Isolation, Structural Elucidation, and Biological Evaluation of a 5-Hydroxymethyl-2furfural Derivative, Asfural, from Enzyme-Treated Asparagus Extract. Journal of Agricultural and Food Chemistry 61, 9155-9159, doi:10.1021/jf402010c (2013).

22. Lees, A. M. et al. Evaluating rumen temperature as an estimate of core body temperature in Angus feedlot cattle during summer. International Journal of Biometeorology 63, 939-947, doi:10.1007/s00484-019-01706-0 (2019).

23. Gavet, O. \& Pines, J. Activation of cyclin B1-Cdk1 synchronizes events in the nucleus and the cytoplasm at mitosis. Journal of Cell Biology 189, 247-259, doi:10.1083/jcb.200909144 (2010).

24. Lindquist, S. THE HEAT-SHOCK RESPONSE. Annual Review of Biochemistry 55, 1151-1191, doi:10.1146/annurev.bi.55.070186.005443 (1986).

25. Yan, L. J. et al. Mouse heat shock transcription factor 1 deficiency alters cardiac redox homeostasis and increases mitochondrial oxidative damage. Embo Journa/ 21, 5164-5172, doi:10.1093/emboj/cdf528 (2002).

26. Sottile, M. L. \& Nadin, S. B. Heat shock proteins and DNA repair mechanisms: an updated overview. Cell Stress \& Chaperones 23, 303-315, doi:10.1007/s12192-017-0843-4 (2018).

27. Bachhawat, A. K. \& Yadav, S. The glutathione cycle: Glutathione metabolism beyond the gammaglutamyl cycle. Iubmb Life 70, 585-592, doi:10.1002/iub.1756 (2018).

28. Tchouague, M., Grondin, M., Glory, A. \& Averill-Bates, D. Heat shock induces the cellular antioxidant defenses peroxiredoxin, glutathione and glucose 6-phosphate dehydrogenase through Nrf2. Chemico-Biological Interactions 310, doi:10.1016/j.cbi.2019.06.030 (2019).

29. Makris, D. P. \& Rossiter, J. T. Domestic processing of onion bulbs (Allium cepa) and asparagus spears (Asparagus officinalis): Effect on flavonol content and antioxidant status. Journal of Agricultural and Food Chemistry 49, 3216-3222, doi:10.1021/jf001497z (2001).

30. Su, Y. Q., Sugiura, K. \& Eppig, J. J. Mouse Oocyte Control of Granulosa Cell Development and Function: Paracrine Regulation of Cumulus Cell Metabolism. Seminars in Reproductive Medicine 27, 32-42, doi:10.1055/s-0028-1108008 (2009).

31. Ito, T. et al. Enzyme-Treated Asparagus Extract Promotes Expression of Heat Shock Protein and Exerts Antistress Effects. Journal of Food Science 79, H413-H419, doi:10.1111/1750-3841.12371 (2014).

32. Sakurai, T. et al. Enzyme-treated Asparagus officinalis Extract Shows Neuroprotective Effects and Attenuates Cognitive Impairment in Senescence-accelerated Mice. Natural Product Communications 9, 101-106 (2014).

33. Nishizawa, M., Kano, M., Okuyama, T., Okumura, T. \& Ikeya, Y. Anti-inflammatory effects of enzymetreated asparagus extract and its constituents in hepatocytes. Functional Foods in Health and 
Disease 6, 91-109 (2016).

34. Lu, X. Y., Xiao, L., Wang, L. \& Ruden, D. M. Hsp90 inhibitors and drug resistance in cancer: The potential benefits of combination therapies of Hsp90 inhibitors and other anti-cancer drugs. Biochemical Pharmacology 83, 995-1004, doi:10.1016/j.bcp.2011.11.011 (2012).

35. Zhao, Y. Q. et al. Geranylgeranylacetone preconditioning may attenuate heat-induced inflammation and multiorgan dysfunction in rats. Journal of Pharmacy and Pharmacology 62, 99-105, doi:10.1211/jpp.62.01.0011 (2010).

36. Santoro, M. G. Heat shock factors and the control of the stress response. Biochemical Pharmacology 59, 55-63, doi:10.1016/s0006-2952(99)00299-3 (2000).

37. Naidu, S. D. \& Dinkova-Kostova, A. T. Regulation of the mammalian heat shock factor 1. Febs Journal 284, 1606-1627, doi:10.1111/febs.13999 (2017).

38. Wu, X. et al. Roles of heat-shock protein 70 in protecting against intestinal mucosal damage. Frontiers in Bioscience-Landmark 18, 356-365, doi:10.2741/4106 (2013).

39. Ogasawara, J. et al. ETAS, an Enzyme-treated Asparagus Extract, Attenuates Amyloid beta-Induced Cellular Disorder in PC12 Cells. Natural Product Communications 9, 561-564 (2014).

40. Wang, Y., Branicky, R., Noe, A. \& Hekimi, S. Superoxide dismutases: Dual roles in controlling ROS damage and regulating ROS signaling. Journal of Cell Biology 217, 1915-1928, doi:10.1083/jcb.201708007 (2018).

41. Poynton, R. A. \& Hampton, M. B. Peroxiredoxins as biomarkers of oxidative stress. Biochimica Et Biophysica Acta-General Subjects 1840, 906-912, doi:10.1016/j.bbagen.2013.08.001 (2014).

42. Brigelius-Flohe, R. Tissue-specific functions of individual glutathione peroxidases. Free Radical Biology and Medicine 27, 951-965, doi:10.1016/s0891-5849(99)00173-2 (1999).

43. Dickinson, D. A. \& Forman, H. J. Cellular glutathione and thiols metabolism. Biochemical Pharmacology 64, 1019-1026, doi:10.1016/s0006-2952(02)01172-3 (2002).

44. Dasgupta, J. et al. Reactive Oxygen Species Control Senescence-Associated Matrix Metalloproteinase-1 Through c-Jun-N-Terminal Kinase. Journal of Cellular Physiology 225, 52-62, doi:10.1002/jcp.22193 (2010).

45. Shirato, K. et al. Enzyme-Treated Asparagus Extract Attenuates Hydrogen Peroxide-Induced Matrix Metalloproteinase-9 Expression in Murine Skin Fibroblast L929 Cells. Natural Product Communications 11, 677-680 (2016).

46. Khadrawy, O. et al. Quercetin supports bovine preimplantation embryo development under oxidative stress condition via activation of the Nrf2 signalling pathway. Reproduction in Domestic Animals 55, 1275-1285, doi:10.1111/rda.13688 (2020).

47. Tubbs, A. \& Nussenzweig, A. Endogenous DNA Damage as a Source of Genomic Instability in Cancer. Cell 168, doi:10.1016/j.cell.2017.01.002 (2017).

48. Cotgreave, I. A. Analytical developments in the assay of intra- and extracellular GSH homeostasis: Specific protein S-glutathionylation, cellular GSH and mixed disulphide compartmentalisation and 
interstitial GSH redox balance (Reprinted from Thiol Metabolism and Redox Regulation of Cellular Functions). Biofactors 17, 269-277, doi:10.1002/biof.5520170126 (2003).

49. Pallardo, F. V., Markovic, J., Garcia, J. L. \& Vina, J. Role of nuclear glutathione as a key regulator of cell proliferation. Molecular Aspects of Medicine 30, 77-85, doi:10.1016/j.mam.2009.01.001 (2009).

50. Steele, M. L. et al. Effect of Nrf2 activators on release of glutathione, cysteinylglycine and homocysteine by human U373 astroglial cells. Redox Biology 1, 441-445, doi:10.1016/j.redox.2013.08.006 (2013).

51. Glory, A. \& Averill-Bates, D. A. The antioxidant transcription factor Nrf2 contributes to the protective effect of mild thermotolerance (40 degrees $\mathrm{C}$ ) against heat shock-induced apoptosis. Free Radical Biology and Medicine 99, 485-497, doi:10.1016/j.freeradbiomed.2016.08.032 (2016).

52. Ichimura, Y. et al. Phosphorylation of p62 Activates the Keap1-Nrf2 Pathway during Selective Autophagy. Molecular Cell 51, 618-631, doi:10.1016/j.molcel.2013.08.003 (2013).

53. Bae, S. H. et al. Sestrins Activate Nrf2 by Promoting p62-Dependent Autophagic Degradation of Keap1 and Prevent Oxidative Liver Damage. Cell Metabolism 17, 73-84, doi:10.1016/j.cmet.2012.12.002 (2013).

54. Ganesan, S. et al. Short-term heat stress causes altered intracellular signaling in oxidative skeletal muscle. Journal of Animal Science 95, 2438-2451, doi:10.2527/jas.2016.1233 (2017).

55. Wu, C. W. et al. Induction of Antioxidant and Heat Shock Protein Responses During Torpor in the Gray Mouse Lemur, Microcebus murinus. Genomics Proteomics \& Bioinformatics 13, 119-126, doi:10.1016/j.gpb.2015.03.004 (2015).

56. Mohammadzadeh, M. et al. Nrf-2 overexpression in mesenchymal stem cells reduces oxidative stress-induced apoptosis and cytotoxicity. Cell Stress \& Chaperones 17, 553-565, doi:10.1007/s12192-012-0331-9 (2012).

57. Leu, J. I. J., Pimkina, J., Frank, A., Murphy, M. E. \& George, D. L. A Small Molecule Inhibitor of Inducible Heat Shock Protein 70. Molecular Cel/ 36, 15-27, doi:10.1016/j.molcel.2009.09.023 (2009).

58. Naidu, S. D., Kostov, R. V. \& Dinkova-Kostova, A. T. Transcription factors Hsf1 and Nrf2 engage in crosstalk for cytoprotection. Trends in Pharmacological Sciences 36, 6-14, doi:10.1016/j.tips.2014.10.011 (2015).

59. Hensen, S. M. M. et al. Activation of the antioxidant response in methionine deprived human cells results in an HSF1-independent increase in HSPA1A mRNA levels. Biochimie 95, 1245-1251, doi:10.1016/j.biochi.2013.01.017 (2013).

60. Hayden, M. S. \& Ghosh, S. Shared principles in NF-kappa B signaling. Cell 132, 344-362, doi:10.1016/j.cell.2008.01.020 (2008).

61. George, L. E., Lokhandwala, M. F. \& Asghar, M. Novel role of NF-kappa B-p65 in antioxidant homeostasis in human kidney-2 cells. American Journal of Physiology-Renal Physiology 302, F1440F1446, doi:10.1152/ajprenal.00006.2012 (2012).

62. Li, J. et al. NF-kappa B regulates HSF1 and c-Jun activation in heat stress-induced intestinal epithelial cell apoptosis. Molecular Medicine Reports 17, 3388-3396, doi:10.3892/mmr.2017.8199 
(2018).

63. Jashni, H. K., Jahromi, H. K., Ranjbary, A. G., Jahromi, Z. K. \& Kherameh, Z. K. Effects of aqueous extract from Asparagus officinalis $\mathrm{L}$. roots on hypothalamic-pituitary-gonadal axis hormone levels and the number of ovarian follicles in adult rats. International Journal of Reproductive Biomedicine $14,75-80$ (2016).

\section{Figures}


Fig 1

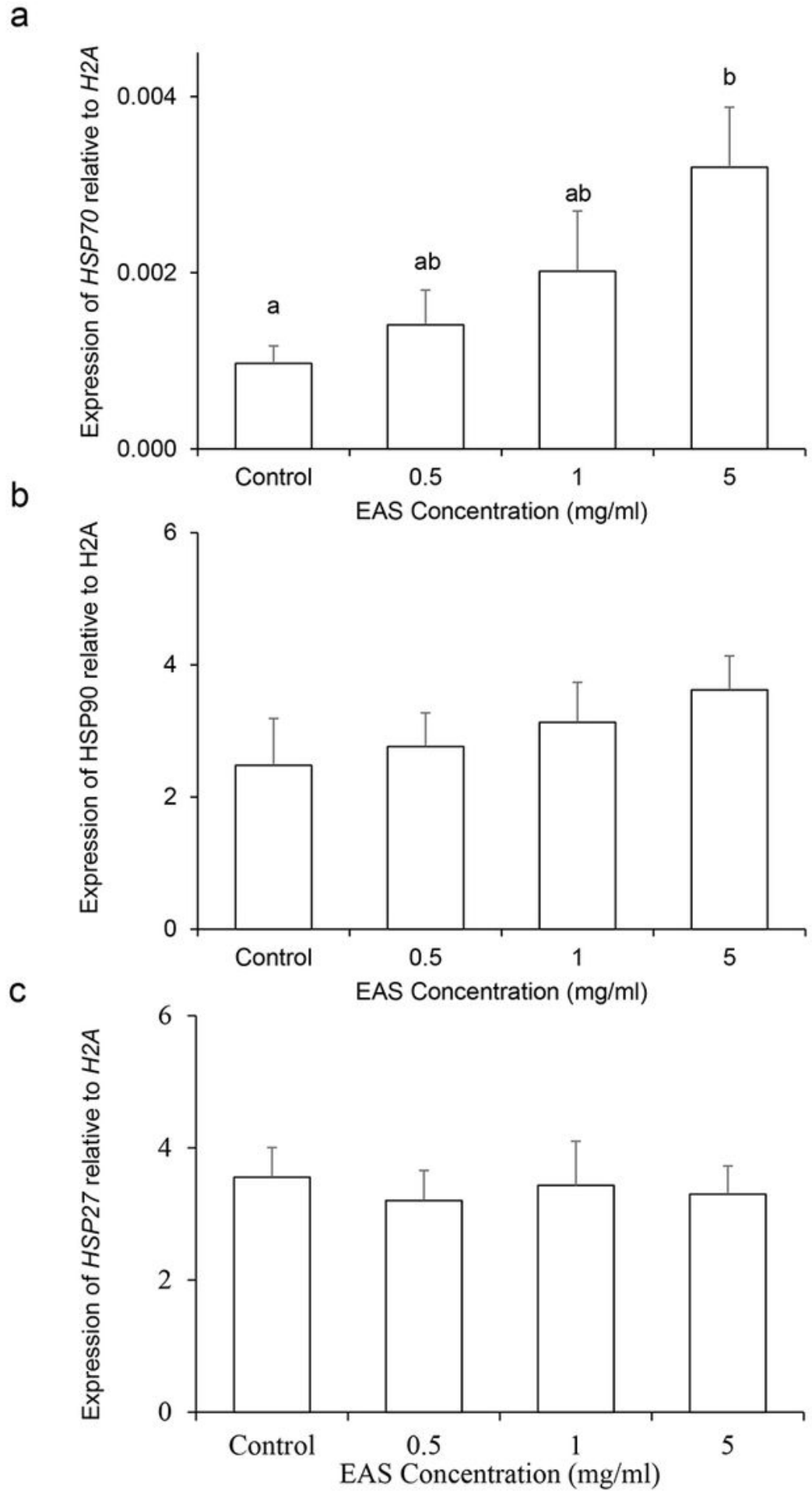

Figure 1

Effect of EAS concentration on the expression of HSP70, HSP90 and HSP27 in bovine cumulusgranulosa cells Cells were treated with various concentration of EAS $(0.5,1$ and $5 \mathrm{mg} / \mathrm{ml})$ for $6 \mathrm{~h}$ at $38.5^{\circ} \mathrm{C}$ and analysed for gene expression. The expression level of HSP70, HSP90 and HSP27 was examined using real time quantitative PCR normalized to H2AFZ as a reference gene. (a) HSP70, (b) HSP90, (c) HSP27. Data are shown as the means \pm SEM, $n=5$, a vs $b(P<0.05)$. 
Fig 2

a
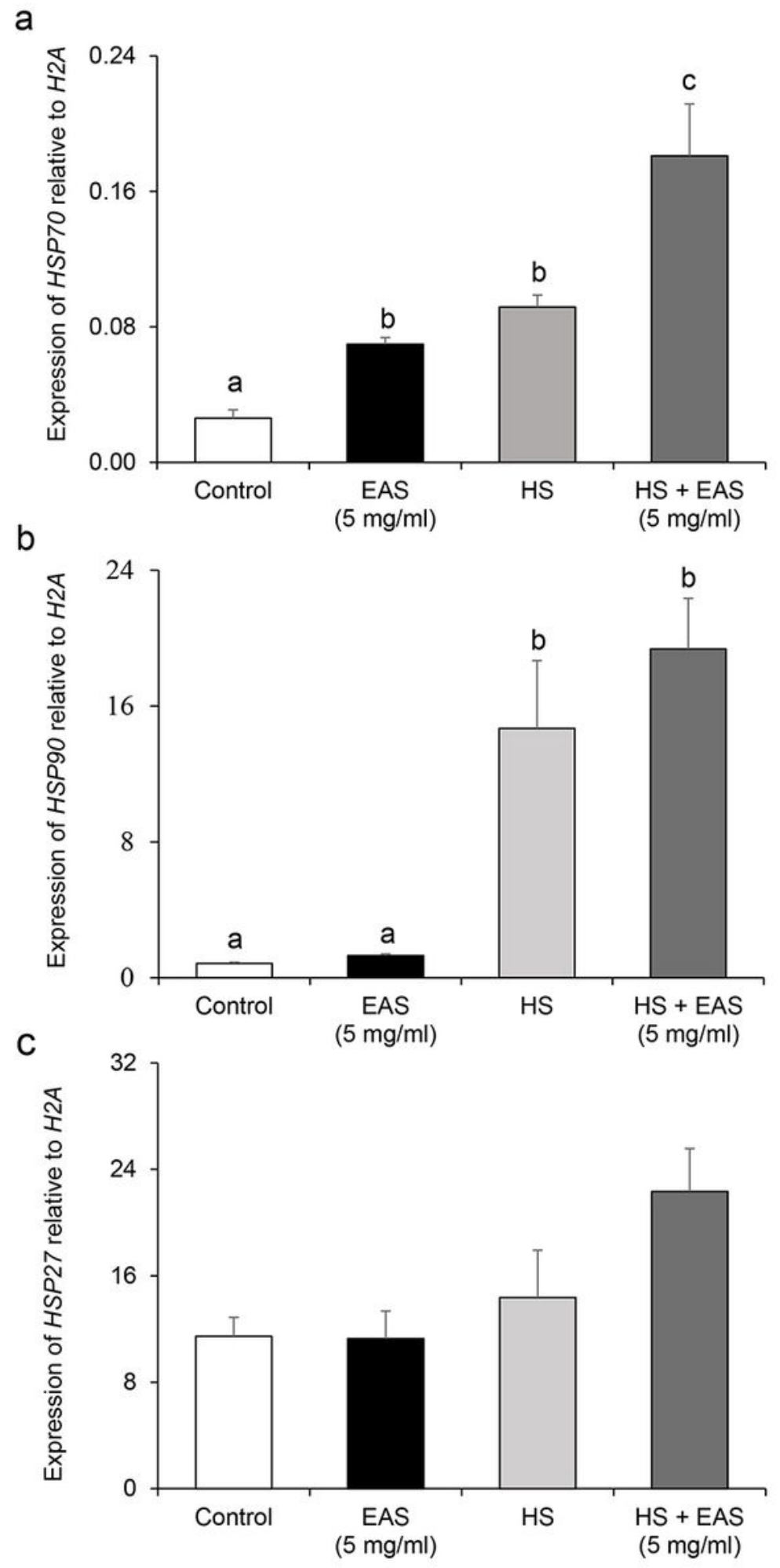

Figure 2

Effect of EAS on the expression of HSP70, HSP90 and HSP27 in bovine cumulus-granulosa cells under non and HS condition Cells were treated for $6 \mathrm{~h}$ with or without EAS $(5 \mathrm{mg} / \mathrm{ml})$ under normal condition at $38.5^{\circ} \mathrm{C}$ (Control, EAS group) and HS condition at $41^{\circ} \mathrm{C}$ (HS, HS + EAS group). (a) HSP70, (b) HSP90, (c) HSP27. Data are shown as the means $\pm S E M, n=5$, a vs $b(P<0.05)$, a vs $c(P<0.01), b$ vs $c(P<0.01)$. 
Fig 3 a

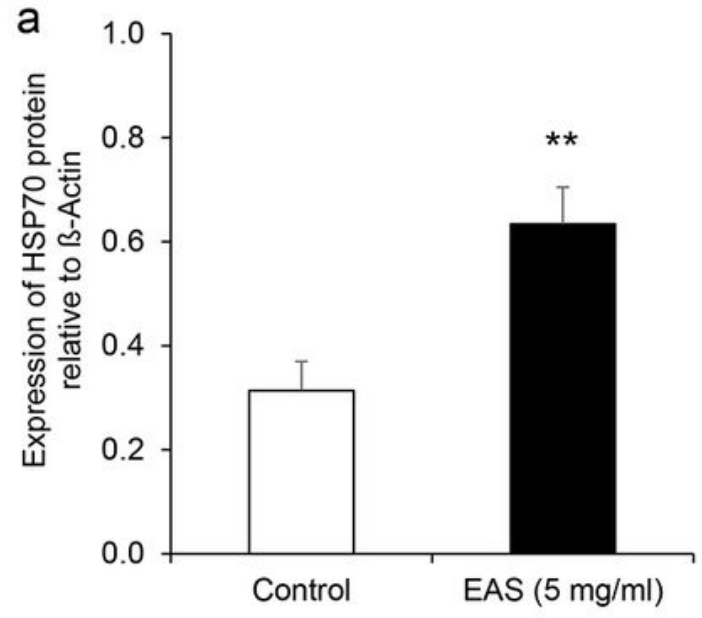

C

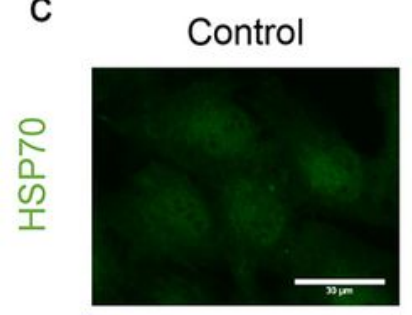

EAS $(5 \mathrm{mg} / \mathrm{ml})$
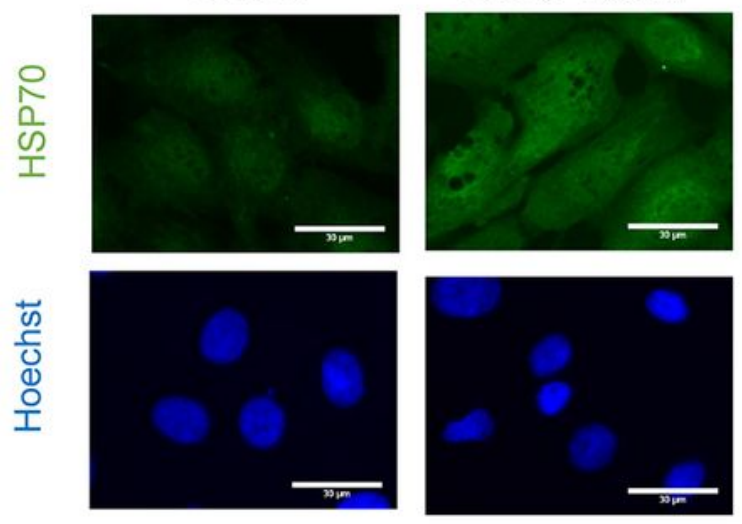

d

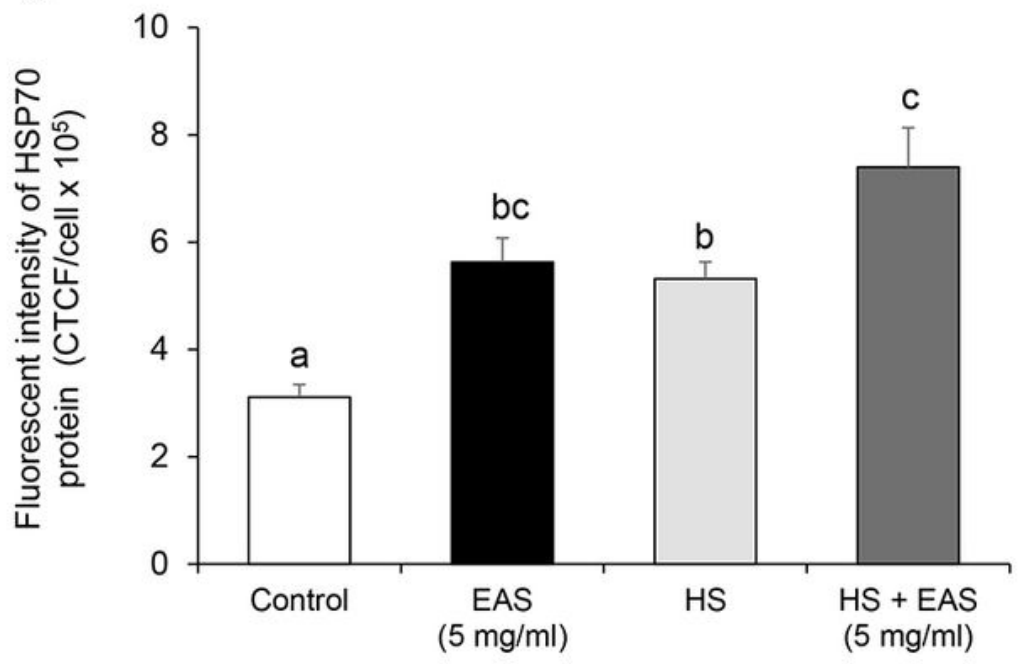

\section{Figure 3}

Effect of EAS on the expression of HSP70 protein in bovine cumulus-granulosa cells Cells were treated with $5 \mathrm{mg} / \mathrm{ml}$ of EAS for $6 \mathrm{~h}$ at $38.5^{\circ} \mathrm{C}$. (a) The expression level of HSP70 protein was normalized to that of the $\beta$-actin. (b) Western blotting elucidates the temporal expression profile of HSP70. (c) Immunostaining for HSP70, image of Hoechst and HSP70. Immunostaining images are shown at magnification $\times 40$ and the scale bar shows $30 \mu \mathrm{m}$. (d) Bars showing CTCF analysis of fluorescence 
intensity. (a) Data are shown as the means $\pm S E M, n=5,{ }^{*} P<0.05$ vs. Control, ${ }^{*} P<0.01$ vs. Control. (d) Data are shown as the means $\pm S E M, n=5$, a vs $b(P<0.05)$, a vs $c(P<0.01)$, b vs $c(P<0.05)$.

Fig 4

a

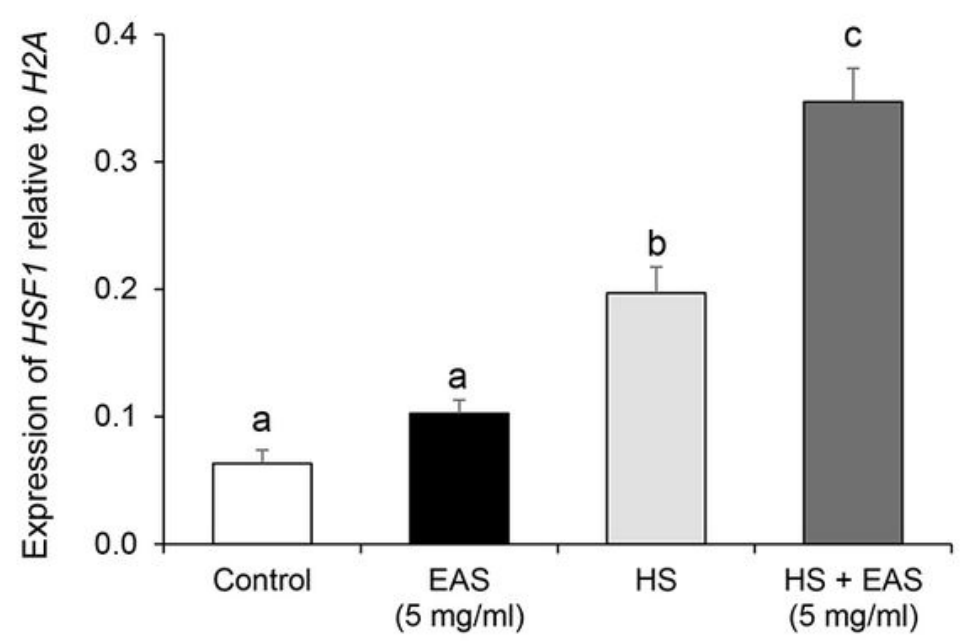

b

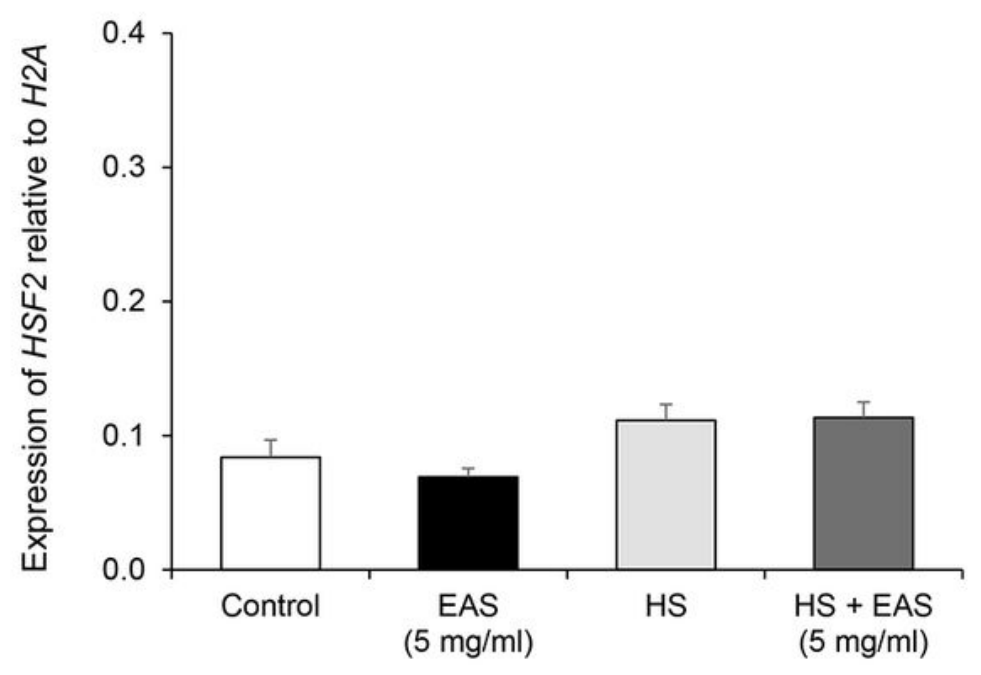

Figure 4

Effect of EAS on the expression of HSF1 and HSF2 in bovine cumulus-granulosa cells under non and HS condition Cells were treated for $6 \mathrm{~h}$ with or without EAS $(5 \mathrm{mg} / \mathrm{ml})$ under normal condition at $38.5^{\circ} \mathrm{C}$ (Control, EAS group) and HS condition at $41^{\circ} \mathrm{C}$ (HS, HS + EAS group). The expression level of (a) HSF1 
and (b) HSF2 was examined using real time quantitative PCR normalized to H2AFZ as a reference gene. Data are shown as the means $\pm S E M, n=5$, a vs $b(P<0.05)$, a vs $c(P<0.01)$, b vs $c(P<0.01)$.

Fig 5

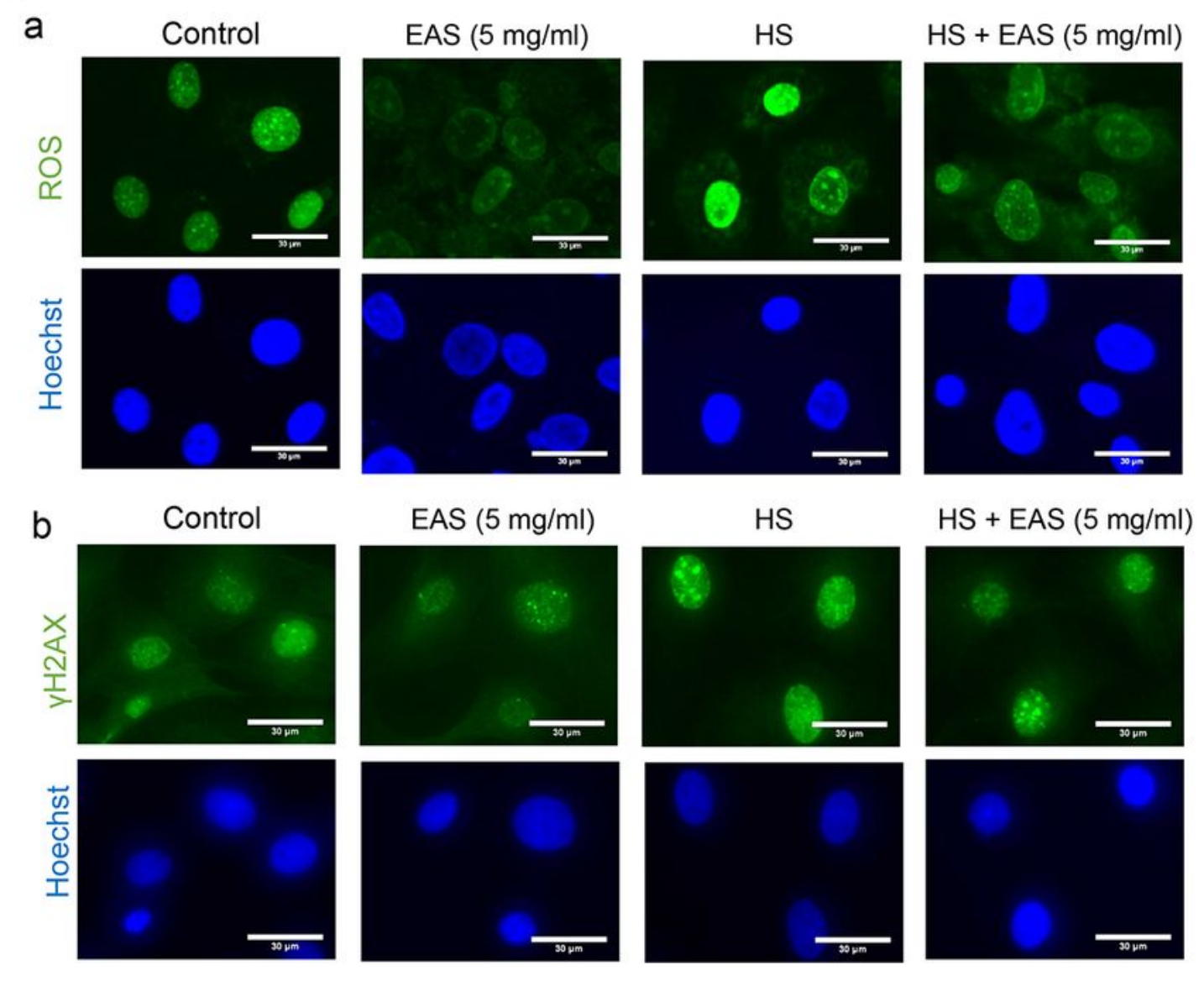

C

d
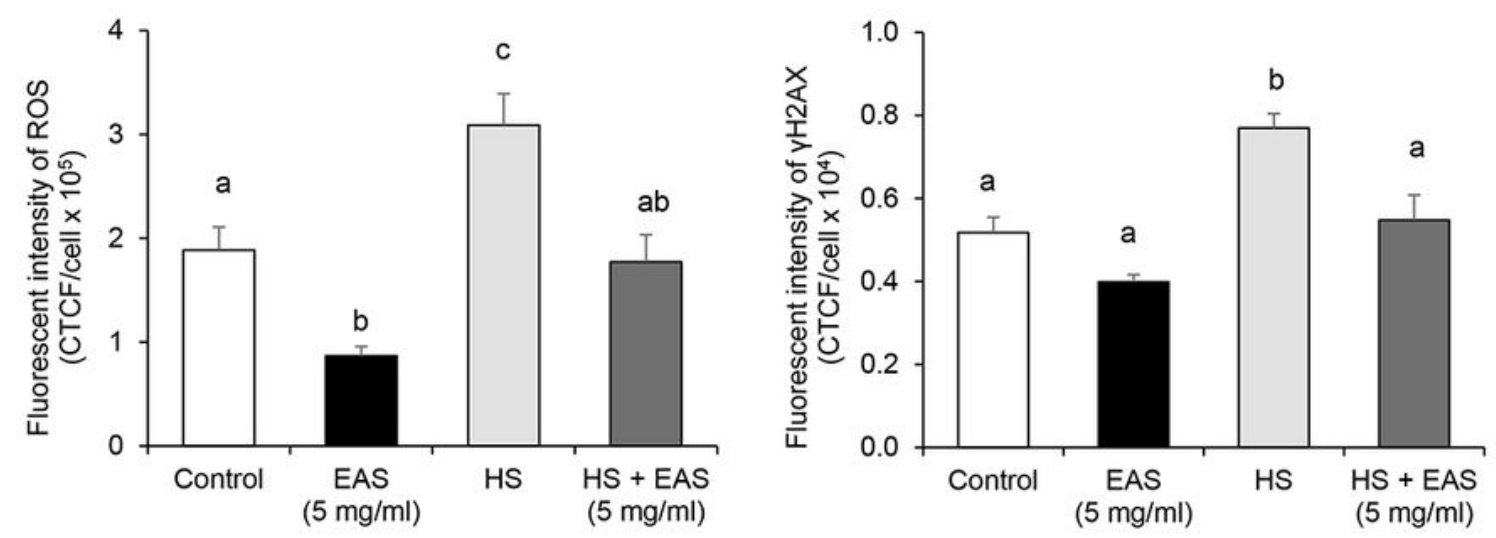

Figure 5

Effect of EAS on induction ROS and DNA damage stained $\mathrm{YH} 2 \mathrm{AX}$ immunostaining in the bovine cumulusgranulosa cells under non and HS condition Bovine cumulus-granulosa cells were treated for $6 \mathrm{~h}$ with or without EAS (5 mg/ml) under normal conditions at $38.5^{\circ} \mathrm{C}$ (Control, EAS group) and HS conditions at 
$41^{\circ} \mathrm{C}$ (HS, HS + EAS group). (a) Fluorescence of ROS (Upper) and nuclei stained with Hoechst (Lower). (b) immunostaining for $\mathrm{YH} 2 \mathrm{AX}$ (Upper) and nuclei stained with Hoechst (Lower). Bar shows $30 \mu \mathrm{m}$. (c)

Fluorescence intensity of ROS (CTCF). Bar shows $30 \mu \mathrm{m}$. (d) Fluorescence intensity of YH2AX (CTCF). (c) Data are shown as the means $\pm S E M, n=5$, a vs $b(P<0.05)$, a vs $c(P<0.001)$, b vs $c(P<0.05)$ and ab vs $c$ $(P<0.01)$. (d) Data are shown as the means $\pm S E M, n=3$, a vs $b(P<0.05)$.

Fig 6

a

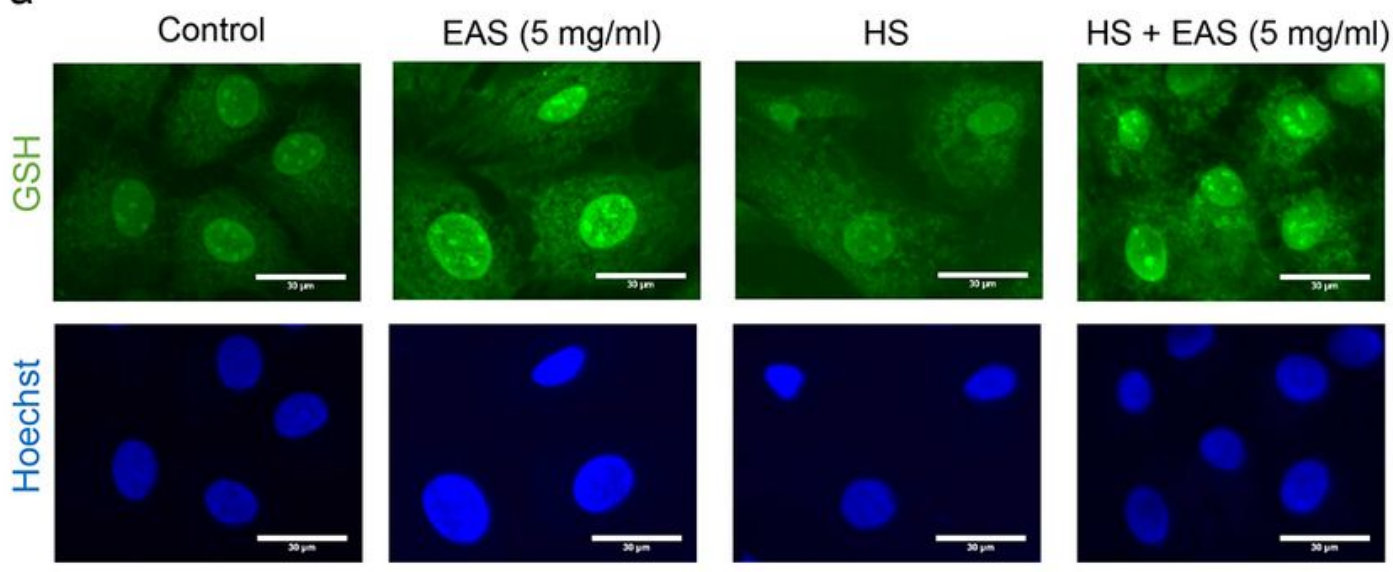

b

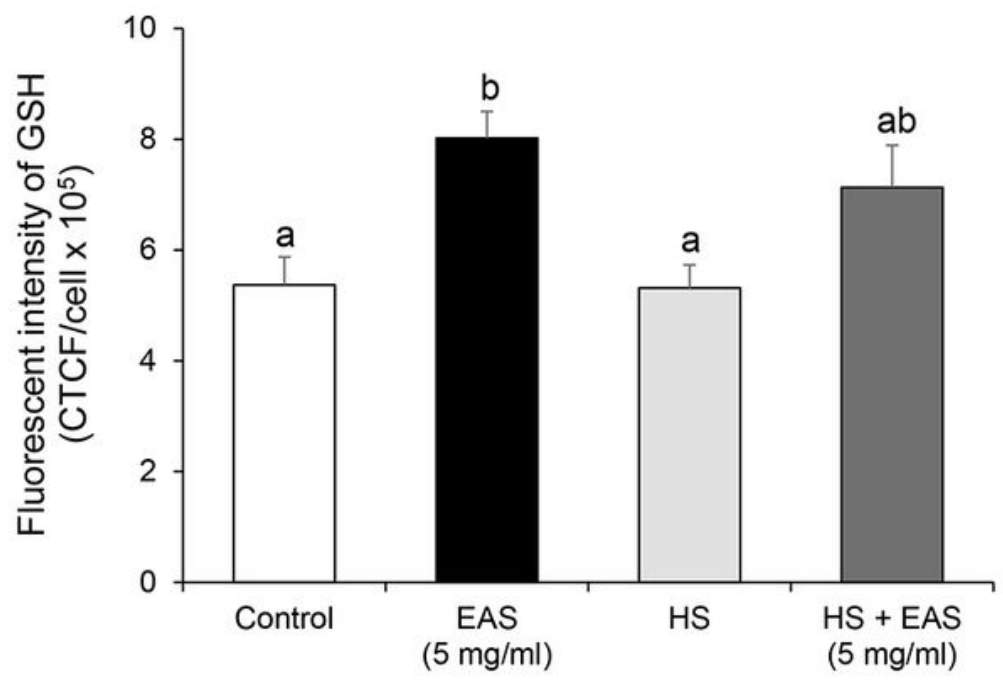

Figure 6 
Effect of EAS on GSH synthesis in the bovine cumulus-granulosa cells under non and HS condition Cells were treated for $6 \mathrm{~h}$ with or without EAS $(5 \mathrm{mg} / \mathrm{ml})$ under normal condition at $38.5^{\circ} \mathrm{C}$ (Control, EAS group) and HS condition at $41^{\circ} \mathrm{C}$ (HS, HS + EAS group). (a) Fluorescence of GSH (Upper) and nuclei stained by Hoechst (Lower). Scale bar shows $30 \mu \mathrm{m}$. (b) Fluorescence intensity of GSH (CTCF). Data are shown as the means $\pm S E M, n=5$, a vs $b(P<0.05)$.

Fig 7 a

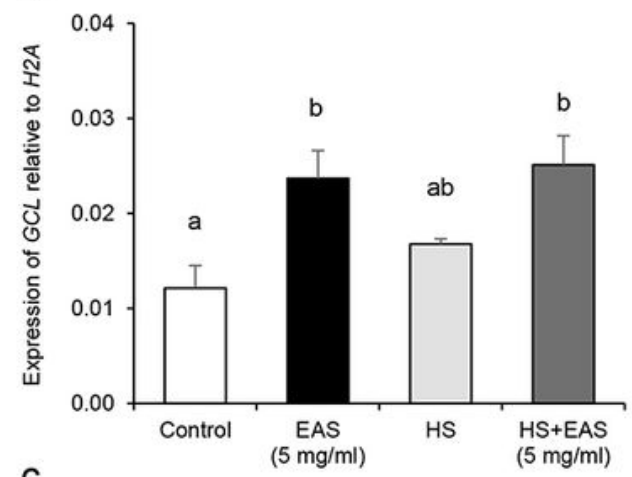

C

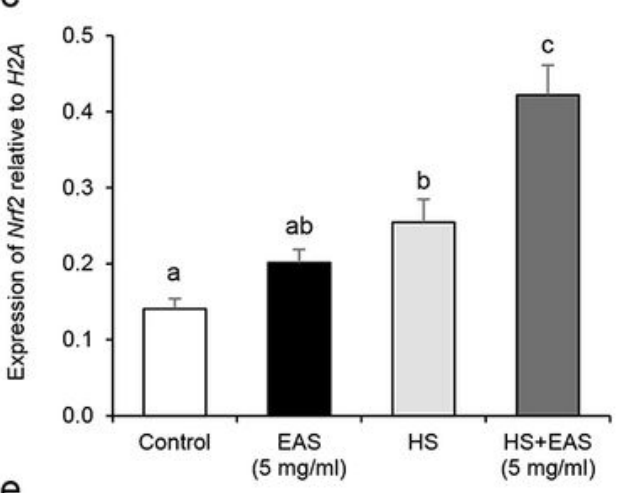

e

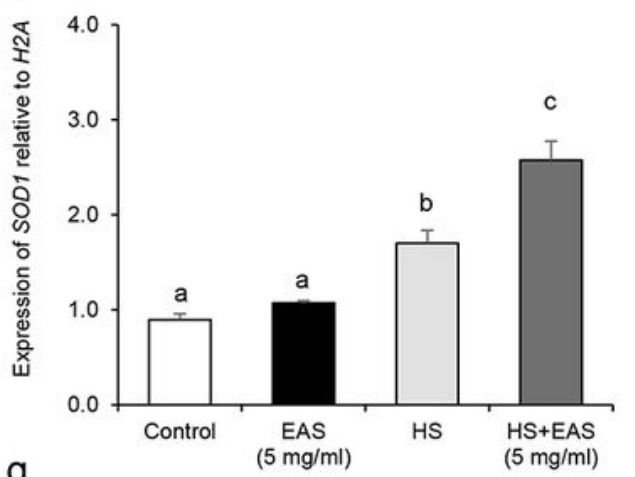

g

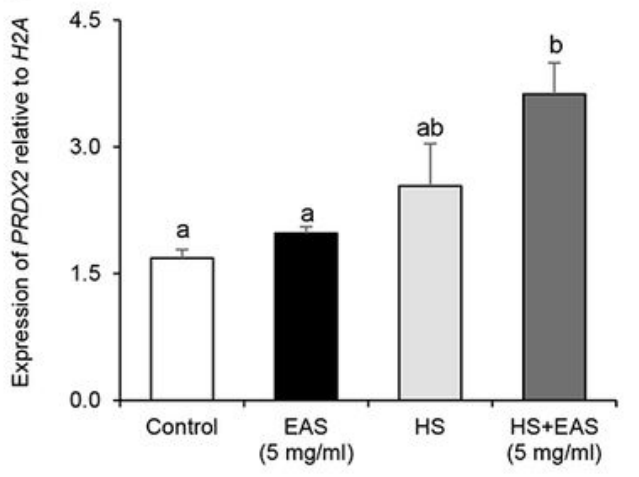

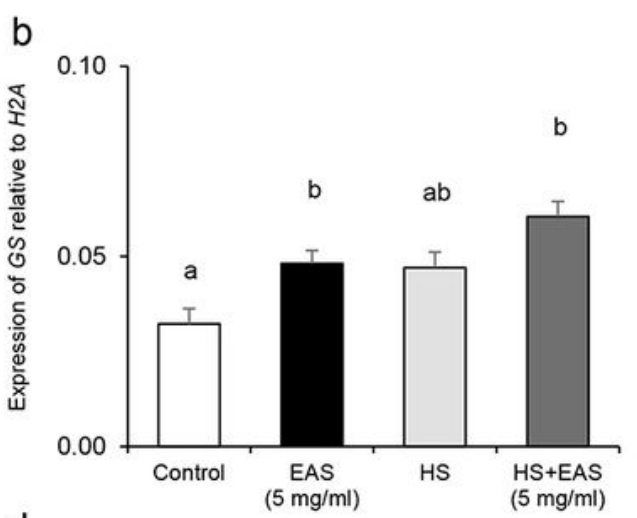
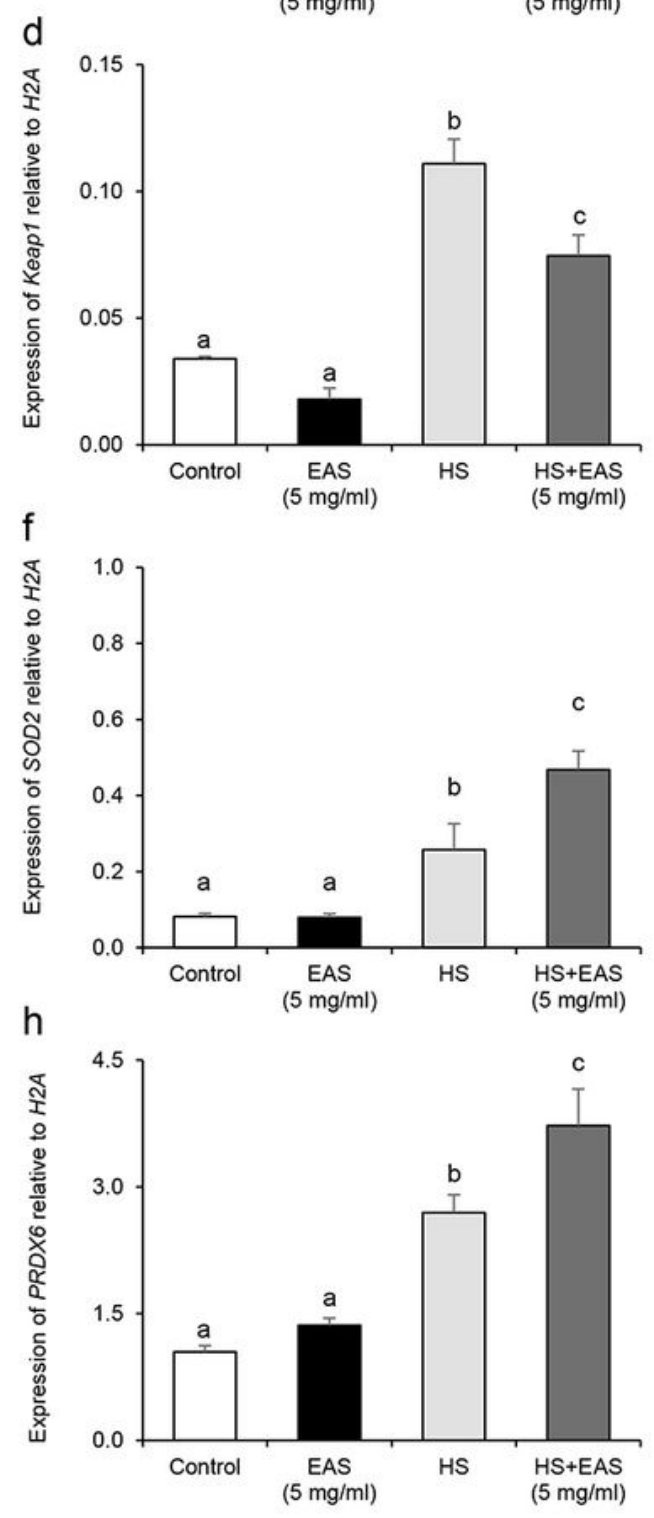

Figure 7 
Effect of EAS on expressions of GS, GCL, Nrf2, Keap1, SOD1, SOD2, PRDX2 and PRDX6 under non- and HS condition Cells were treated for $6 \mathrm{~h}$ with or without EAS $(5 \mathrm{mg} / \mathrm{ml})$ under normal condition at $38.5^{\circ} \mathrm{C}$ (Control, EAS group) and HS condition at $41^{\circ} \mathrm{C}$ (HS, HS + EAS group). The expression level of GS, GCL, Nrf2, Keap1, SOD1, SOD2, PRDX2 and PRDX6 was examined using real time quantitative PCR normalized to H2AFZ as a reference gene. (a) GCL, (b) GS, (c) Nrf2, (d) Keap1, (e) SOD1, (f) SOD2, (g) PRDX2, (h) PRDX6. Data are shown as the means $\pm S E M, n=5$, Means with different letters $(a \sim c)$ at each mRNA are significantly different $(p<0.05)$.

Fig 8

a
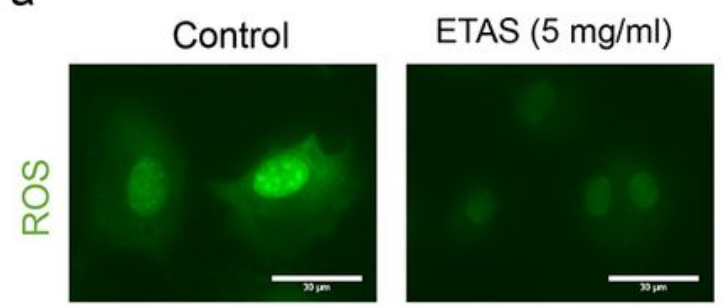

$E T A S+P E S$
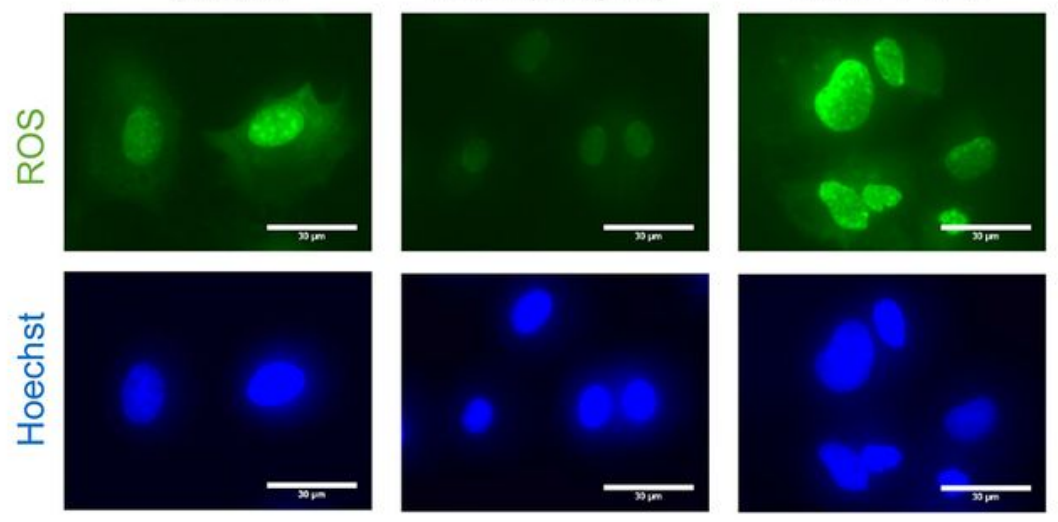

b

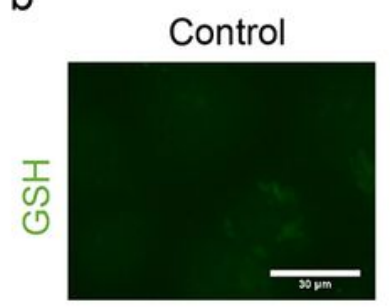

$\operatorname{ETAS}(5 \mathrm{mg} / \mathrm{ml})$
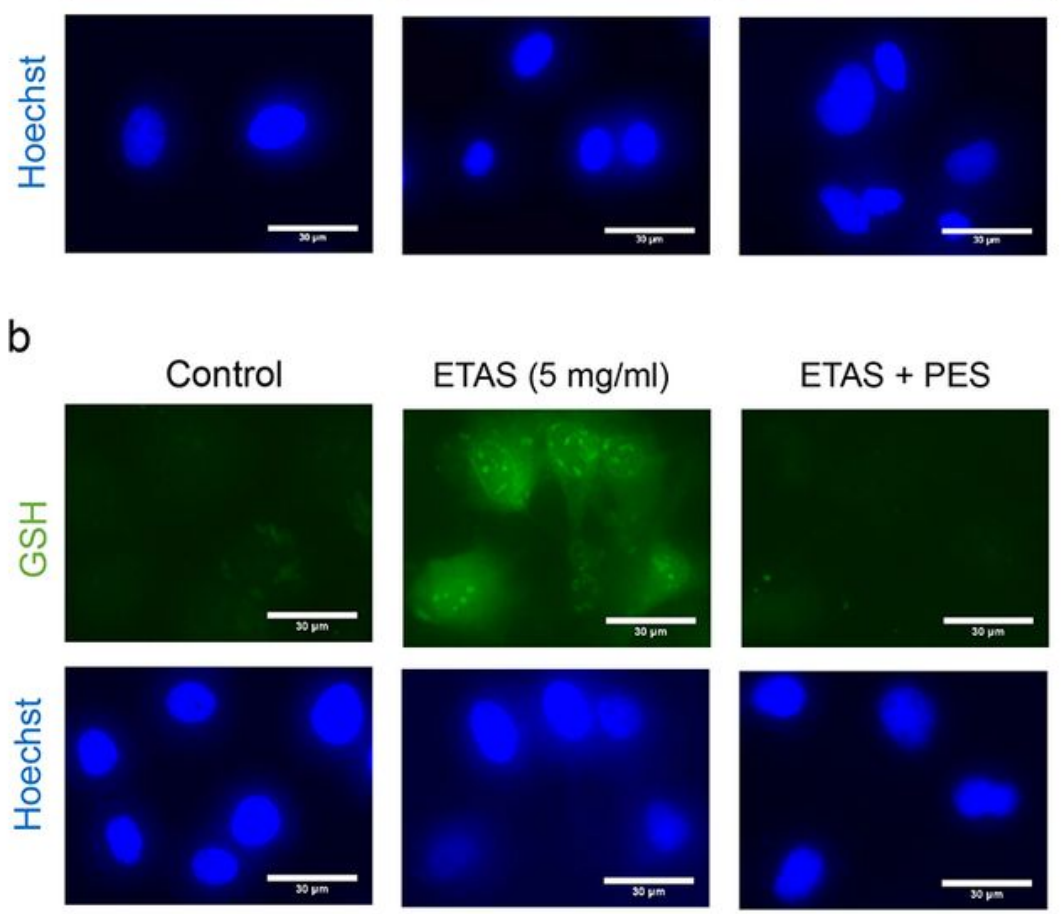

$E T A S+P E S$
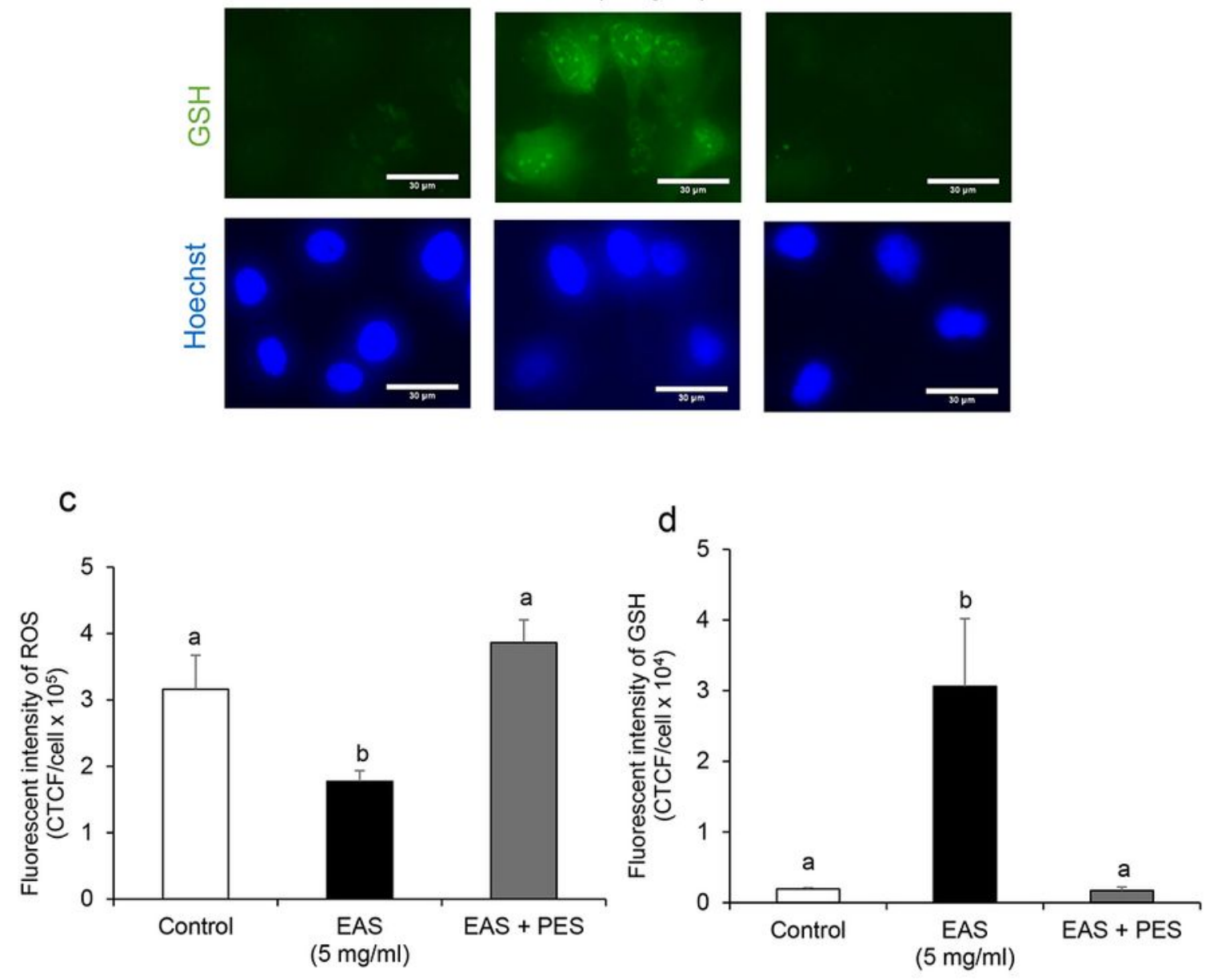


\section{Figure 8}

Effect of EAS-induced HSP70 inhibition on GSH synthesis and ROS generation in bovine cumulusgranulosa cells Cells were treated for $6 \mathrm{~h}$ with or without EAS $(5 \mathrm{mg} / \mathrm{ml})$ under normal conditions at $38.5^{\circ} \mathrm{C}$ (Control, EAS group) and $10 \mu \mathrm{M}$ PES together with $5 \mathrm{mg} / \mathrm{ml}$ EAS (EAS + PES). (a) Fluorescence of ROS (Upper) and nuclei stained by Hoechst (Lower). (b) Fluorescence of GSH (Upper) and nuclei stained with Hoechst (Lower). Scale bar shows $30 \mu \mathrm{m}$. (c) Fluorescence intensity of ROS (CTCF). Bar shows 30 $\mu \mathrm{m}$. (d) Fluorescence intensity of GSH (CTCF). (c) Data are shown as the means $\pm S E M, n=5$, $a$ vs $b$ $(P<0.05)$. (d) Data are shown as the means $\pm S E M, n=5$, a vs $b(P<0.01)$. 
Fig 9
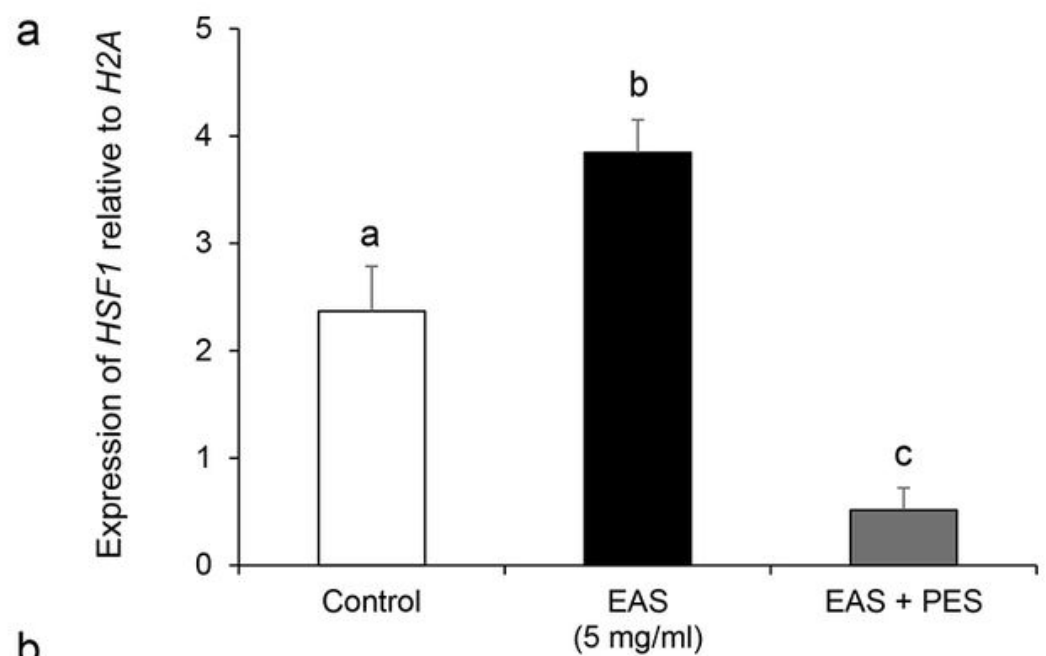

b
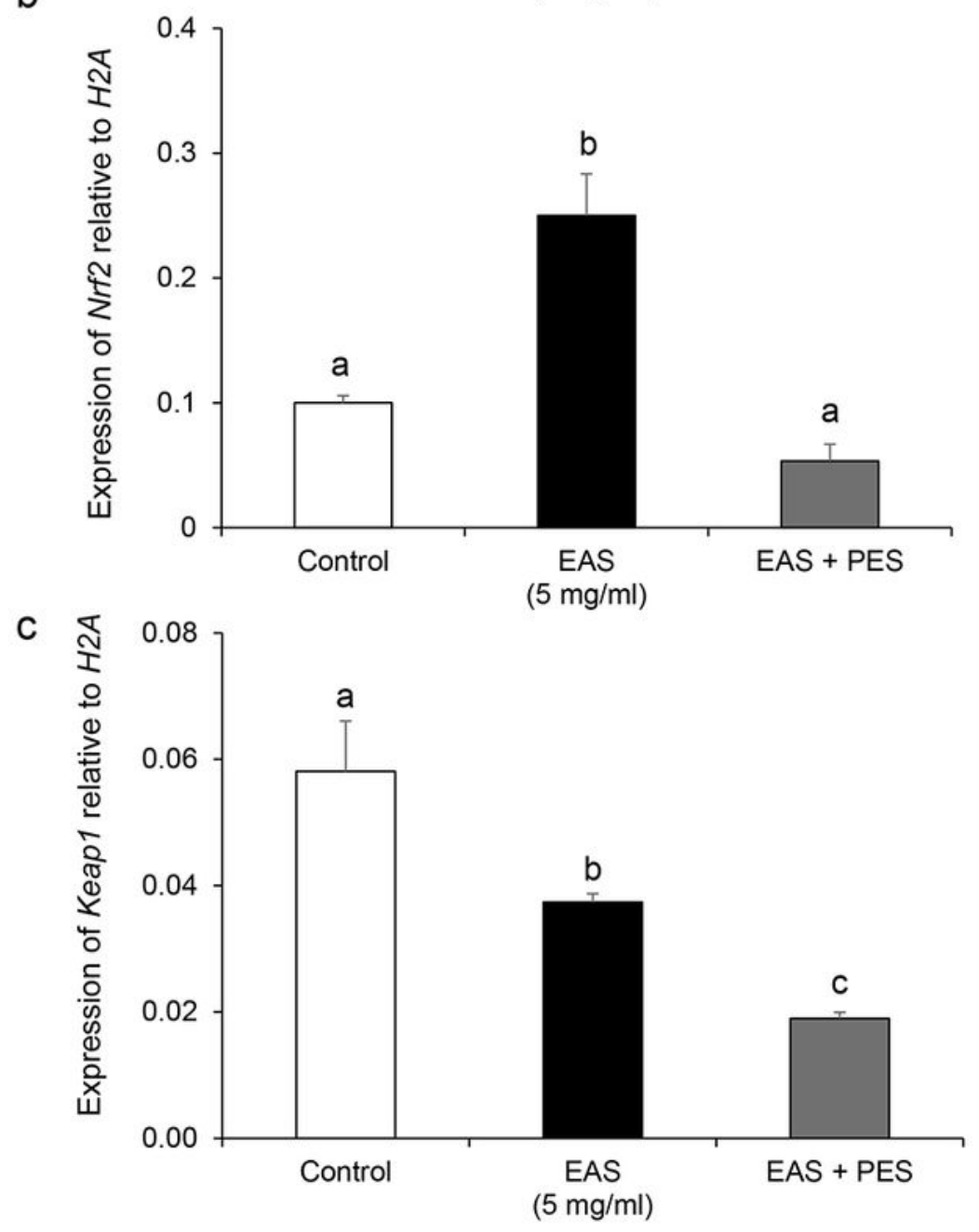

Figure 9

Effect of EAS-induced HSP70 inhibition on expression of HSF1, Nrf2 and Keap1 Cells were treated for 12 $\mathrm{h}$ with or without EAS $(5 \mathrm{mg} / \mathrm{ml})$ under normal condition at $38.5^{\circ} \mathrm{C}$ (Control, EAS group) and $10 \mu \mathrm{M}$ PES together with $5 \mathrm{mg} / \mathrm{ml}$ EAS (EAS + PES). The expression level of HSF1, Nrf2 and Keap1 was examined using real time quantitative PCR normalized to H2AFZ as a reference gene. (a) HSF1, (b) Nrf2. Data are 
shown as the means $\pm S E M, n=5$, a vs $b(P<0.01)$, a vs $c(P<0.05)$, b vs $c(P<0.01)$. (c) Keap1. Data are shown as the means $\pm S E M, n=5$, a vs $b(P<0.05)$, a vs $c(P<0.001)$, b vs $c(P<0.05)$.

Fig 10

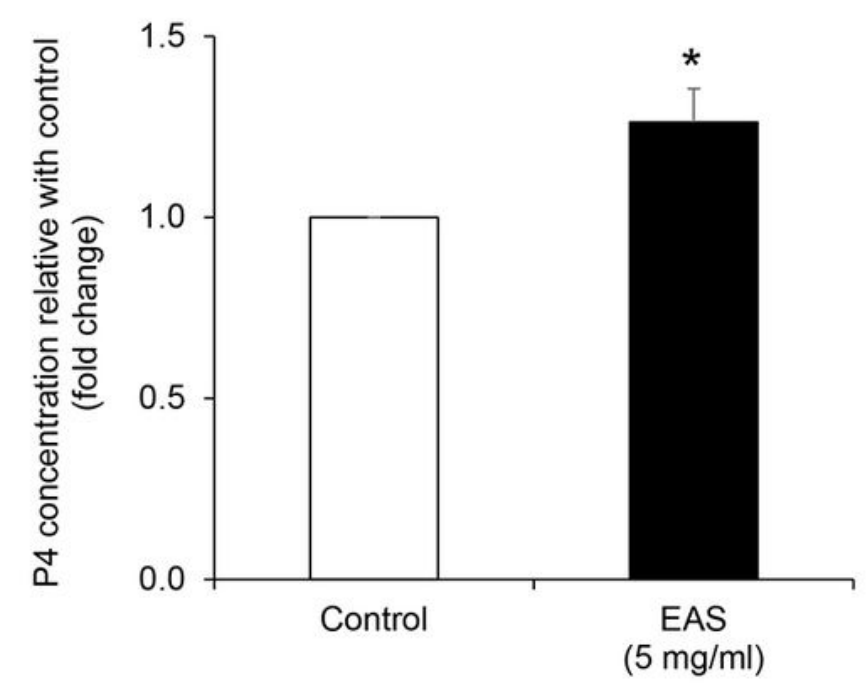

Figure 10

Effect of EAS on P4 synthesis in bovine cumulus-granulosa cells Cells were treated for $12 \mathrm{~h}$ with or without EAS $\left(5 \mathrm{mg} / \mathrm{ml}\right.$ ) under normal conditions at $38.5^{\circ} \mathrm{C} \mathrm{h}$ (Control, EAS group). Data are shown as the means $\pm S E M, n=8,{ }^{*}<<0.05$ vs. Control. 


\section{Supplementary Files}

This is a list of supplementary files associated with this preprint. Click to download.

- CTSKoisupplTable1.docx

- CTSKhoiSupplFig.pdf 